\title{
Salt-dependent hypertension and inflammation: targeting the gut-brain axis and the immune system with Brazilian green propolis
}

\author{
Marcos Adriano Carlos Batista ${ }^{1}\left[\right.$. Daiane Cristina de Assis Braga ${ }^{1}\left[\right.$ - Sandra Aparecida Lima de Moura ${ }^{3}$ (1) \\ Gustavo Henrique Bianco de Souza ${ }^{2}(\mathbb{0})$. Orlando David Henrique dos Santos ${ }^{2}(1)$. Leonardo Máximo Cardoso ${ }^{1}(1)$
}

Received: 25 May 2020 / Accepted: 30 July 2020 / Published online: 12 August 2020

(c) Springer Nature Switzerland AG 2020

\begin{abstract}
Systemic arterial hypertension (SAH) is a major health problem around the world and its development has been associated with exceeding salt consumption by the modern society. The mechanisms by which salt consumption increase blood pressure (BP) involve several homeostatic systems but many details have not yet been fully elucidated. Evidences accumulated over the last 60 decades raised the involvement of the immune system in the hypertension development and opened a range of possibilities for new therapeutic targets. Green propolis is a promising natural product with potent anti-inflammatory properties acting on specific targets, most of them participating in the gut-brain axis of the sodium-dependent hypertension. New anti-hypertensive products reinforce the therapeutic arsenal improving the corollary of choices, especially in those cases where patients are resistant or refractory to conventional therapy. This review sought to bring the newest advances in the field articulating evidences that show a cross-talking between inflammation and the central mechanisms involved with the sodium-dependent hypertension as well as the stablished actions of green propolis and some of its biologically active compounds on the immune cells and cytokines that would be involved with its anti-hypertensive properties.
\end{abstract}

Keywords Green propolis $\cdot$ Sodium $\cdot$ Hypertension $\cdot$ Inflammation $\cdot$ Cytokines $\cdot$ Sympathetic drive

Leonardo Máximo Cardoso

leonardo.cardoso@ufop.edu.br

Marcos Adriano Carlos Batista

marcos.carlos@ufop.aluno.edu.br

Daiane Cristina de Assis Braga

daiane.braga@ufop.aluno.edu.br

Sandra Aparecida Lima de Moura

sandramoura@ufop.edu.br

Gustavo Henrique Bianco de Souza

guhbs@ef.ufop.br

Orlando David Henrique dos Santos

orlando@ufop.edu.br

1 Department of Biological Sciences, Institute of Exact and Biological Sciences, Federal University of Ouro Preto, Morro Do Cruzeiro, Ouro Preto, MG 35400-000, Brazil

2 Department of Pharmacy, Pharmacy School, Federal University of Ouro Preto, Ouro Preto, MG, Brazil

3 Department of Environmental Engineering, Mines School, Federal University of Ouro Preto, Ouro Preto, MG, Brazil

\section{Introduction}

High-sodium intake has been long associated with physiological adaptations in a number of contra-regulatory mechanisms that, somehow, lead to SAH while tries to reconcile hydroelectrolytic balance back within homeostatic boundaries. Therefore, an increment in sodium intake is accompanied by an increased sodium absorption by the gut, what triggers key mechanisms involving endocrine, neural, cardiovascular and renal systems that, as a whole, handle the sodium content within extracellular fluid so that the extra sodium absorbed is excreted to preserve the required sodium levels to keep homeostasis (Karppanen and Mervaala 2006). On an ongoing basis, the continuous activation of such regulatory systems seems to contribute to the development of hypertension by mechanisms that are not yet fully understood.

Over the last 60 years, many studies have revealed the role of the immune system and inflammation on SAH development and maintenance with particular attention to salt-dependent hypertension (Abais-Battad et al. 2015; 
Rucker et al. 2018; Wade et al. 2016; Wenzel et al. 2016). The anti-hypertensive effect of immunosuppression seems the most compelling evidence indicating that the interaction between the immune system and key regulatory mechanisms controlling BP is, somehow, linked to SAH (Li et al. 2020; Moreira et al. 2019; Shi et al. 2010). Yet, the exogenous administration of pro-inflammatory molecules in normotensive experimental animals is correlated with high BP what provides further support to the role of the immune system for hypertension development (Shi et al. 2010; Vasdev et al. 2011; Wei et al. 2015). However, the importance of the immune system to the individual survival poses serious limitations to immunosuppression therapies and is highly unlike to suit long-lasting treatments like the usual ones in hypertension management. To fully explore the immunotherapeutic potential in SAH treatment, it becomes critical to identify and better understand specific components of the immune system and the precise immunological mechanisms that pathogenically contribute to hypertension development as well as the outcomes of targeting such components and mechanisms with bioactive molecules.

Currently, treatment of SAH uses a variety of drugs already available on market such as angiotensin-converting enzyme (ACE) inhibitors, $\mathrm{AT}_{1}$ receptor antagonists, calcium channel inhibitors, diuretics, and beta-blockers (Bouhanick et al. 2019). However, about $20 \%$ of the hypertensive population has resistance to conventional treatment (Carey et al. 2018; Daugherty et al. 2012; Muxfeldt et al. 2019). Within this population of patients resistant to treatment, about $8 \%$ develop refractory arterial hypertension, which is set at the moment that SAH treatment fails to reduce BP despite the use of 5 or more classes of anti-hypertensive drugs (Muxfeldt et al. 2019). Based on the statistics regarding patients resistant and refractory to conventional treatment of hypertension, new therapeutic tools and medicine are required to treat such condition. Medicines based on natural products have proven effective in treating many chronic diseases, including SAH, and, for this reason, have attracted great scientific interest due to their high popularity and therapeutic effects (Hadi et al. 2019). Experimental and clinical evidences indicate that green propolis, a resinous material produced by honeybees from material collected from the Baccharis dracunculifolia (DC) plant, has potential to treat hypertension and, possibly, improve the treatment of resistant hypertension. Most of the biological effects attributed to DC, green propolis and constitutive components are related to its anti-inflammatory properties (de Figueiredo-Rinhel et al. 2019; Okamoto et al. 2012), angiotensin-converting enzyme inhibitor-like effect (Kwon et al. 2006), vascular activity (Kubota et al. 2004) and diuretic properties (El Menyiy et al. 2018) studied in different experimental models of hypertension.
In this review, we sought to line out some of latest advances in the role of the immune system on BP control and salt-dependent hypertension development through the gut-brain axis as well as the potential anti-hypertensive effects of green propolis base on its anti-inflammatory properties and effects through neurogenic mechanisms.

\section{Hypertension and high-sodium intake: long story short}

Systemic arterial hypertension is characterized by a sustained increase in BP levels. SAH is currently considered a public health problem, affecting roughly 1.5 billion people, and it is also one of the biggest causes of death worldwide (WHO 2012). This clinical condition is an important risk factor for several diseases such as ischemic brain infarction, intracranial hemorrhage, myocardial infarction, and congestive heart failure (APA 2020; WHO 2012). It has been widely documented that smoking (Groppelli et al. 1992), alcoholism (Lima et al. 1999), sedentarism (Alvarez Li et al. 1999) and eating habits (Yamamoto-Kimura et al. 1996) are important factors associated to the development of SAH. Among eating habits, salt intake plays a key role in the development of SAH (Grillo et al. 2019) and will be further discussed here. Sodium is an essential mineral, usually found in its ionized form $\left(\mathrm{Na}^{+}\right)$within the body fluids, especially in the extra-cellular fluid. It plays an important role in regulating cellular volume and, thereby, cellular concentration of several signaling components within the cells as well as propagation of electrical impulses along the plasma membrane (Guyton et al. 1972). Therefore, its concentration in the body fluids is tightly regulated by several redundant mechanisms that controls sodium intake and excretion (Stanhewicz and Larry Kenney 2015). Daily salt intake recommendations usually follow assessments based on physiological parameters, especially the plasma renin activity and its correlation with salt intake in different mammal species, including the humans (Bie and Evans 2017). However, clinical and experimental evidences have suggested that chronic activation of such mechanisms during high-sodium intake can result in BP regulation disfunctions and increased BP as detailed discussed elsewhere (Bie and Evans 2017; Karppanen and Mervaala 2006).

Several key systems are implicated in SAH development and the common sense amongst researchers is that neural, renal and local (vascular) mechanisms are the major involved in the process (Bie and Evans 2017). Between the 70 's and the early 90's, Guyton and cols. propose a model of blood volume and pressure regulation in which an acute increase in circulating volume (which could be caused by a sudden increase in salt intake followed by high-water intake) is promptly compensated by an increase water as sodium 
excretion by the kidney as a result of an increase in cardiac debit and, therefore, blood pressure - the so-called pressurenatriuresis mechanism-(Guyton 1989, 1991; Guyton et al. 1972). Renal medulla plays a pivotal role in the pressurenatriuresis mechanism, because renal medullary blood flow is poorly autoregulated, unlike whole kidney blood flow and glomerular filtration rate (Cowley et al. 1992). Along with increased medullary flow due to increase systemic blood pressure, several molecular mechanisms, including inflammatory processes, take place in the medullary portion of the tubules to prevent sodium reabsorption thus increasing sodium excretion and reduces blood volume (Cowley et al. 1992). It has been proposed that an impairment in such mechanisms is the primary responsibility for the loss in renal ability of handling excess sodium intake thus leading to hypertension (Ivy and Bailey 2014; Rucker et al. 2018), and might be especially important when renal tissue is damaged by chronic handling of large amounts of sodium. As a consequence, an imbalance between sodium intake and excretion would favor sodium accumulation in the extracellular fluid. Sodium accumulation results in osmotic changes that activate counter-regulatory mechanisms which promote greater water reabsorption in the kidneys and thirst (Bourque 2008). Collectively, these mechanisms result in water accumulation, what keeps sodium concentration normal, but lead to an increase in blood volume and thus, in BP. For these reasons, renal system has been pointed as the major ruler in high-blood pressure development for at least 40 years.

Nevertheless, further advances in the physiology field revealed that the central nervous system (CNS) also play an important role in SAH development due to high-salt intake. The involvement of neurogenic mechanisms and the sympathetic tone has been extensively studied and, despite the difficulties in establishing a complete and clear picture of how disfunction the sympathetic control of the blood pressure contribute to hypertension (Bie and Evans 2017), several pieces of evidence support the importance of these mechanisms in the development of high BP levels as a consequence of high-sodium intake (Bie and Evans 2017; Guyenet 2006). Dating back to the mid of the twentieth century, the lack of drug treatments for hypertension then led to the use of surgical procedures which consisted of sympathetic ganglionectomy and was referred as a tool to treat patients with severe and refractory hypertension at that time (Peet and Isberg 1946; Smithwick and Thompson 1953). Also, celiac ganglionectomy proved efficient in mitigating hypertension development in an experimental model of salt-angiotensin II-dependent hypertension (King et al. 2007) and modern experimental studies have reported that renal sympathetic denervation has also the potential to treat hypertension (Bertog et al. 2012). Yet, it has been reported that at least 50\% of patients with essential hypertension display augmented levels of renal norepinephrine spillover despite the fact that considerable overlapping in the levels of renal epinephrine does exist among hypertensive and normotensive patients (Esler 2015). Renal norepinephrine comes mainly from sympathetic endings which release the neurotransmitter on an ongoing basis (Guyenet 2006). Because the tissue norepinephrine levels depend on nerve fibers release, the rates of degradation/uptake and diffusion across the tissue make the interpretation of the results somehow difficult and must be evaluated carefully (Bie and Evans 2017). Limitations apart, many authors have used norepinephrine spillover as a tool to index sympathetic tone dysfunctions to a specific tissue and its correlation with most cases of hypertension corroborates this idea (Bie and Evans 2017). The discussion extends to the fact that frequency of sympathetic bursts in multifiber recordings from peroneal nerve is elevated in hypertensive patients compared to normotensive (Schlaich et al. 2004), and several other forms of hypertension such as those related to obesity or obstructive sleep apnoea (Schlaich et al. 2004) as well as in other pathological conditions like heart failure, hemorrhage and dehydration (Guyenet 2006). Collectively, evidence strongly suggests that dysfunctions in sympathetic regulation by the central nervous system play an important role in SAH development. The remaining questions rely on what neurogenic dysfunctions play a primary role in SAH development or if they are consequence of other systemic dysfunctions like in the renal system. At least for sodium-dependent hypertension, data from our group are aligned with the hypothesis that neurogenic dysfunctions may develop early, before renal damage, in a salt-dependent hypertension model where rats are exposed to mild sodium overload diet from weaning (Gomes et al. 2017).

The relation between high-salt intake and sympatheticrelated hypertension has been grounded on a large body of evidences suggesting that changes in sympathetic regulation affect not only renal function at several levels but also vascular capacitance and resistance, especially the splanchnic bed (King et al. 2007; Osborn et al. 2008), despite the parallel in humans is still unclear and require further studies (Weinberger 2006). High-sodium intake was clearly demonstrated to increase the excitability of neuronal populations in the central nervous system that comprehends the rostral ventral part of the medulla, the so-called rostroventrolateral medulla (RVLM), and this increase in RVLM neurons excitability is greatly correlated to increased blood pressure levels (Adams et al. 2007). This portion of the medulla encloses the main source of pre-motor sympathetic neurons within the central nervous system (Guyenet 2006) and is largely responsible for the sympathetic drive to peripheral organs. Interestingly, the increase in the adrenal and lumbar sympathetic drive due to high-sodium artificial cerebrospinal fluid (aCSF) infusion in the lateral ventricles is accompanied by renal sympathetic drive depression, indicating that sympathetic control driven by sodium within the central nervous system seems 
to follow the organotopy theory (Guyenet 2006; McAllen and Dampney 1990). Such theory states that separate groups of RVLM neurons preferentially controls different vascular beds or organs (Guyenet 2006). This concept and the abovementioned findings reveal the complexity of the sodiumdriven changes in sympathetic control by the central nervous system and raise some potential problems related to widespread targets in many anti-hypertensive therapeutic profiles.

\section{Sodium and osmotic driven control of the sympathetic drive}

Ongoing sympathetic nerve activity can be either withdrawn or enhanced according to the nature of the deviation in the sensory mechanisms allowing short- and long-term stabilization of BP (Guyenet 2006). Many sensory mechanisms take place in such process and here we will discuss those strictly related to sodium in the extracellular fluid. Sodium concentration, in the extracellular fluid figures around $150 \mathrm{mmol} / \mathrm{L}$, is tightly regulated and deviations from this set point can be detected either by osmoregulatory (Bourque 2008) or sodium-sensing (Noda and Hiyama 2015b) mechanisms located peripherally (peripheral osmoreceptors) or centrally (central osmoreceptors and sodium sensors). Central circuitry responsible for the osmotic-triggered contra regulatory mechanisms is scattered throughout the brain and involves mainly the hypothalamus and the medulla oblongata (Bourque 2008). Changes in extracellular fluid osmolarity, including those in the brain, are accompanied by sympathetic nerve activity responses aiming the re-establishment of normal extracellular osmolality levels, usually by changing sodium concentration or water content in the extracellular fluid (Bourque 2008; Toney and Stocker 2010). It had been postulated that continuous activation of such a mechanism could, somehow, contribute to dysfunction in the sympathetic drive control and, thus, to the development of hypertension (Toney and Stocker 2010). Parallel to the osmoregulatory mechanisms, recent studies have identified and described a new set of molecular mechanisms that detect increases in extracellular sodium concentration within the brain and translate such information in activation of mechanisms related to the control of descending sympathoexcitatory pathways and blood pressure (Nomura et al. 2018). The response to an increase in sodium concentration is triggered by a sodium channel $\left(\mathrm{Na}_{x}\right)$ located in the astrocytes cells within the organum vasculosum of the lamina terminalis (OVLT) and subfornical organ (SFO) (Noda and Hiyama 2015a; Nomura et al. 2018). Those same regions are also known to participate in the osmoregulatory response (Bourque 2008) and now, it seems reasonable that osmotic and sodium-sensing mechanisms regulating blood pressure may share some neuronal pathways but are still distinguished one from another regarding the nature of the stimuli. However, if those mechanisms are designed to tightly regulate body fluid volume and composition, sympathetic activation driven by them would have only temporary effects on blood pressure and once extracellular fluid is restored to its original composition, the stimulus would cease as well. Based on this assumption, it seems unlikely that such mechanisms could contribute to long-lasting changes in sympathetic drive and high blood pressure levels as observed in salt-dependent hypertension. Therefore, how increased salt intake would contribute to hypertension?

As a matter of fact, many studies, including one by our group, have demonstrated that high-salt intake is associated with increased concentration of sodium in the cerebrospinal fluid (CSF) and that other hypertensive models like the renovascular display increased CSF sodium concentration as well (Gomes et al. 2017; Haywood et al. 1984; Leenen et al. 2002) without changes in plasma sodium concentration (Gomes et al. 2017). Choroid plexus (ChP) is located within the ventricles of the brain, produces CSF and form an interface that regulates the trafficking of ions, water and cells between the peripheral blood and the CSF (Brown et al. 2004). Few pieces of evidence have showed possible mechanisms regulating sodium permeability in the ChP. Even though many ion exchangers and channels are involved in CSF ion composition, $\mathrm{ENaC}$ is the most explored due to the role sodium in the extracellular fluid osmolarity and electrical properties of the brain. $\mathrm{ENaC}$ and mineralocorticoid (an important hormone related to sodium metabolism) receptors were found to be colocalized in the choroid plexus and paraventricular nucleus suggesting a possible regulation of $\mathrm{ENaC}$ expression by mineralocorticoids (Amin et al. 2005). How that kind of regulation might occur under highsodium intake is poorly understood. However, experimental findings have reported that central nervous system $\mathrm{ENaC}$, especially those found in the ChP, mediate the hypertensive response in a mouse model of Liddle syndrome as well as a greater increase in blood pressure due to $\mathrm{Na}^{+}$-rich CSF infusion into lateral brain ventricles of these mice (Huysse et al. 2012). Corroborating these finding, a following study with mice knockout for the gene Nedd4-2, which negatively regulates $\mathrm{ENaC}$ expression, showed that $\mathrm{ENaC}$ in the kidney, choroid plexus and brain nuclei was enhanced and that such phenotype produced higher increase in BP due to high-salt diet without affect the increase in BP produced by subcutaneous infusion of Ang II (Leenen et al. 2015). The results suggest that increased $\mathrm{ENaC}$ expression in the brain of Nedd4-2-/- mice mediates their hypertensive response to a high-salt diet by causing increased sodium levels in the CSF, as well as hyperresponsiveness to CSF sodium (Huysse et al. 2012). Furthermore, intracerebroventricular injection of high-sodium artificial CSF (aCSF) in normotensive rats increased sympathetic drive and led to hypertension 
(Huang et al. 1998). This finding is corroborated by findings of Stocker and cols. showing that acute infusion of highsodium aCSF in the lateral ventricle of normotensive rats elicits a transient increase in sympathetic drive and blood pressure (Stocker et al. 2015). Some of the mechanisms discussed here are summarized in Fig. 1.

Currently, increased interest has been raised on the interaction between systemic inflammation and the brain. $\mathrm{ChP}$ also constitutes a barrier between blood and CSF with a remarkably high rate of secretion controlling the trafficking not only of ions but also of signaling molecules and inflammatory cells from capillary blood. Therefore, $\mathrm{ChP}$ is an important site for communication and regulation of peripheral and central inflammatory cross-talking. Among the findings supporting such a role, mRNA expression for the pro-inflammatory cytokines IL- $1 \beta$ and TNF- $\alpha$ were increased in LPS-induced systemic inflammation (Marques et al. 2007) and ChP enhances CSF secretion in response to local inflammation due to brain hemorrhage (Karimy et al. 2017). Therefore, ion secretion into CSF by ChP could be

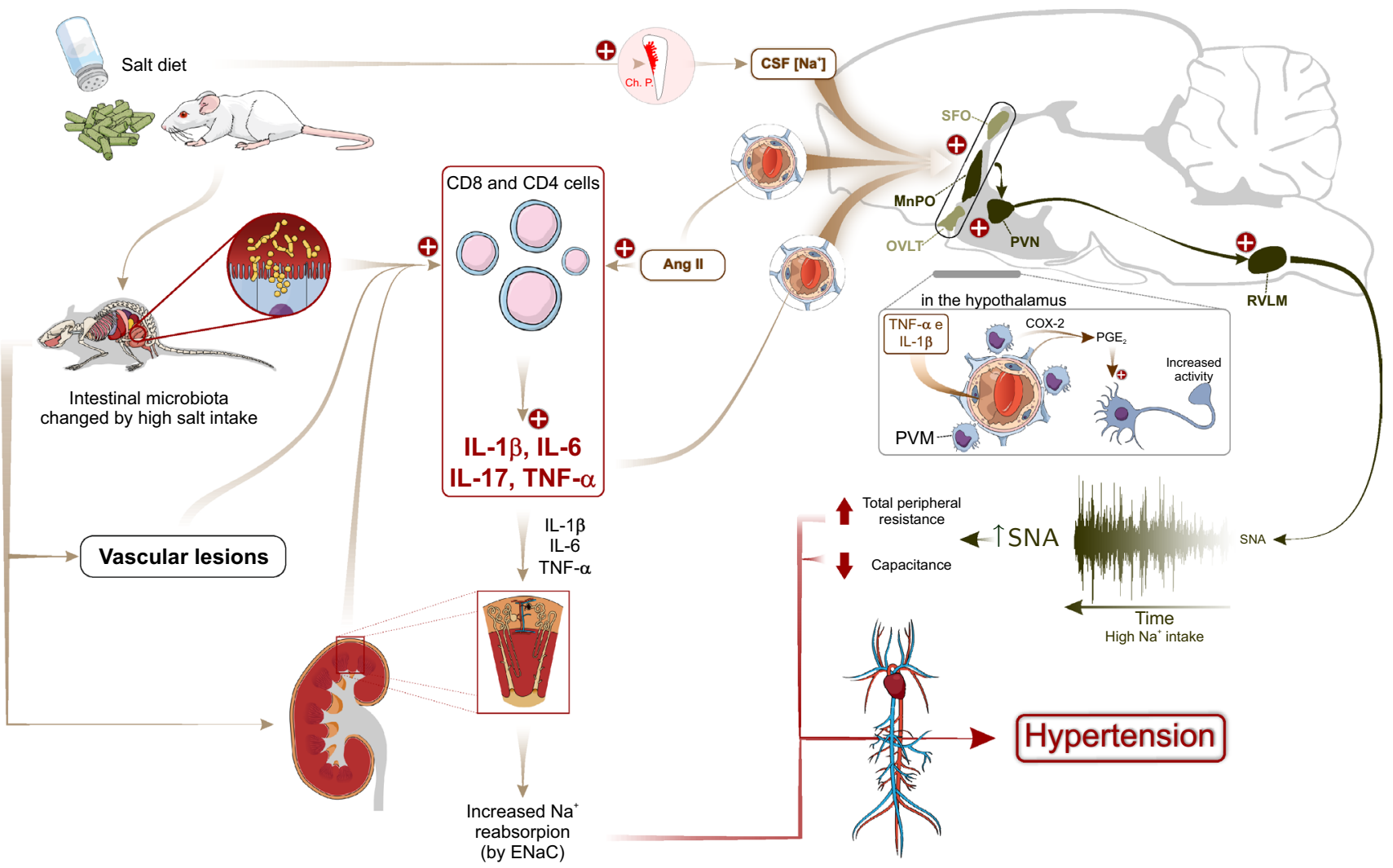

Fig. 1 Proposed hypothesis of how high-salt intake and the immune system contribute to hypertension development. Increase of salt intake leads to change in intestinal microbiota, vascular lesion, kidney inflammation and increase of $\mathrm{Na}^{+}$in CSF. Change in intestinal microbiota diversity, vascular lesions and kidney inflammation are accompanied by CD 8 and CD4 lymphocytes resulting in increased IL-1 $\beta$, IL-6, IL-17 and TNF- $\alpha$ production and release in loco and in the blood stream. Increased CSF $\left[\mathrm{Na}^{+}\right]$would result from changes in the choroid plexus (Ch. P.) channels and transporters expression due to peripheral signaling mechanisms involving endogenous ouabain-like molecule (Huang et al. 1998). The role of inflammatory cytokines on Ch. P. channels expression is still unknown. Both, increased CSF $\left[\mathrm{Na}^{+}\right]$and cytokines would act on central targets associated to transduction of the input signals in the lamina terminalis (SFO and OVLT) through sodium sensing mechanisms (Noda and Hiyama 2015a), $\mathrm{AT}_{1}$ receptors, and activation of COX-2-derived prostaglandins $\left(\mathrm{PGE}_{2}\right)$ resulting in increased neuronal firing probability in sympathetic pathways of the paraventricular nucleus (PVN) and rostral ventrolateral medulla (RVLM), increased sympathetic drive to the cardiovascular system and increased blood pressure. Despite the fact that angiotensin II (Ang II) levels are expected to reduce with higher sodium intake (Thomson et al. 2006), tissue angiotensinergic mechanism seem more active in the central nervous system (Gomes et al. 2017) and can also stimulate the proliferation of resident lymphocytes by activation of $\mathrm{AT}_{1}$ receptors expressed in its plasma membrane of these cells and stimulate secretion of TNF- $\alpha$, TGF- $\beta$ and MCP cytokines. Cytokines produce changes in renal sodium handling mechanisms resulting in increased epithelial sodium channels expression and increased $\mathrm{Na}^{+}$ reabsorption, what may contribute to high-blood pressure development. $I L-1 \beta$ interleukin $1 \beta, I L-6$ interleukin $6, I L-17$ interleukin 6 , $T N F-\alpha$ tumor necrosis factor- $\alpha, C O X-2$ cyclooxygenase-2, $P G E_{2}$ prostaglandin E2, Ch. $P$ choroid plexus, $C S F$ cerebrospinal fluid, $\mathrm{Na}^{+}$sodium, $\mathrm{SFO}$ subfornical organ, $\mathrm{MnPO}$ median preoptic nucleus, OVLT organum vasculosum of the lamina terminalis, $P V N$ hypothalamic paraventricular nucleus, $R V L M$ rostral ventrolateral medulla, SNA sympathetic nerve activity, $B P$ blood pressure 
under influence of inflammatory signaling molecules as also demonstrated for aldosterone and endogenous ouabain-like compound (Huang et al. 1998; Leenen 2010). On the other hand, many in vitro and in vivo studies have also showed high sodium can stimulating the production of pro-inflammatory cytokines such as TNF- $\alpha$, IL-1 $\beta$, IL-6 and IL-17, and induce differentiation of $\mathrm{T}_{\mathrm{H}} 17$ cells without having any direct effect on murine myeloid dendritic cells generation, maturation or function (Jörg et al. 2016; Kleinewietfeld et al. 2013; Wilck et al. 2017; Zhang et al. 2015a). Since high-sodium diet seems to correlate with high-CSF sodium concentration, these findings indicate that increased sodium concentration in CSF might be corroborating a process of brain inflammation in individuals under high-sodium diet suggesting that brain inflammation could play an important role in SAH development through mechanisms involving functional dysfunctions in $\mathrm{ChP}$ due to high-sodium intake.

\section{The role of the immune system in hypertension: a new paradigm}

At this point, it seems undoubtful that high-salt intake has a causal relation to hypertension. However, it is still not clear how high-salt intake leads to neural adaptations that contribute to hypertension? In the last 3 decades, a number of studies have been dedicated to the understanding of how blood pressure can be regulated by the immune system as well discussed by Rucker and cols (Rucker et al. 2018). This idea began to be shaped by Guzik and cols. in 2007 when it was demonstrated that $\mathrm{T}$ cells were required for the full development of angiotensin II (Ang II)-induced hypertension in mice (Guzik et al. 2007). Since then, many authors have focused their attention on the role of $\mathrm{T}$ cells in the pathogenesis of hypertension, although many other players in the inflammatory process could contribute to SAH development.

Data from studies with hypertensive patients showed that they have a higher fraction of immunosenescent, proinflammatory, perforin ${ }^{+}$, granzyme $\mathrm{B}^{+}$, INF- $\gamma^{+}$and TNF- $\alpha^{+}$cytotoxic $\mathrm{CD} 8^{+} \mathrm{T}$ cells in the peripheral blood when compared to normotensive age- and sex-matched subjects (Youn et al. 2013) as well as increased CD4 cells, especially the CD4 $\mathrm{T}_{\mathrm{H}} 17$ population (Itani et al. 2016), suggesting that $\mathrm{T}$ cells are, somehow, related to hypertension development. Significant accumulation of CD8 cells was found in the tubulointerstitium of hypertensive patients with nephrosclerosis compared to normotensive subjects (Youn et al. 2013) suggesting that they play a role in the functional changes that take place in the kidney of such individuals and contribute for hypertension development as well (Rucker et al. 2018; Youn et al. 2013). Substantiating the role of CD8 cells in hypertension development, mice lacking CD8 T cells (CD8-/-) were protected from Ang II-induced hypertension and vascular dysfunction (Trott et al. 2014) showing the critical need for this cell type in the mechanisms by which Ang II produced high blood pressure experimentally. On the other hand, mice lacking CD4 T cells (CD4-/-) were not protected from Ang II-induced hypertension, suggesting that hypertensive mechanisms activated by Ang II rely on inflammatory pathways dependent on CD8 cells (Trott et al. 2014) instead. Ang II is an important hormone from the renin-angiotensin system that plays a pivotal role in blood pressure regulation and hydroelectrolytic balance (Santos et al. 2018). Interestingly, an interplay between Ang II and immune systems seems to exist in such a way that not only immune system can influence the Ang II pressor effects but, Ang II by itself can stimulate the proliferation of lymphocytes through $\mathrm{AT}_{1}$ receptors expressed on plasma membrane of splenic lymphocytes (Nataraj et al. 1999). Also, Ang II stimulates the release of inflammatory mediators such as TNF- $\alpha$, TGF- $\beta$, and monocyte chemoattractant protein-1 (MCP-1) in renal tissue through a mechanism that involves NF- $\kappa B$ activation (Klahr and Morrissey 1998) possibly because of Ang IIdriven infiltration of inflammatory cells in the renal tissue. On the other hand, the activation of $\mathrm{AT}_{1}$ receptors on macrophages seems to have an anti-inflammatory effect since peritoneal macrophages from animals lacking $\mathrm{AT}_{1}$ receptors have enhanced expression of pro-inflammatory markers such as monocyte chemoattractant protein, TNF- $\alpha$ and IL-1 $\beta$ (Ma et al. 2011). It seems that $\mathrm{AT}_{1}$ stimulation on macrophages provides a feedback mechanism meant to temper the inflammatory response due to increases in Ang II stimulation (Rucker et al. 2018). From a clinical perspective, however, the effects of Ang II on T cells seem less compelling since Itani and cols. have demonstrated that Ang II had no direct effect on cytokine production by human T cells (Itani et al. 2016) suggesting that Ang II-driven increase in blood pressure through inflammatory mechanisms might involve other players than only stimulation of $\mathrm{T}$ cells or indirect stimulation mechanisms.

As discussed previously, CNS plays a pivotal role in blood pressure regulation and many forms of hypertension. Inflammation development in cardioregulatory centers of CNS has been associated with enhanced sympathetic drive, resulting in BP increase, whereas inhibition of this inflammation ameliorates hypertension (Xue et al. 2016; Yu et al. 2010). For instance, chimeric spontaneously hypertensive rats (SHR) reconstituted with Wistar-Kyoto (WKY) bone marrow resulted in significant $\mathrm{BP}$ reduction associated with attenuation of both central and peripheral inflammation. On the other hand, elevated BP along with increased central and peripheral inflammation was observed in chimeric WKY rats reconstituted with SHR bone marrow (Santisteban et al. 2015). Findings in this study strongly suggest that extravasation of bone-marrow-derived cells to the PVN is an important mechanism corroborating the high blood pressure 
development when chimeric animals was challenged with an chronic infusion of Ang II (Santisteban et al. 2015). The trafficking of circulating immune cells into the CNS is believed to involve increased permeability of the blood-brain barrier due to hypertension (Biancardi et al. 2014; Ueno et al. 2004). Such increase in permeability would also allow systemic Ang II to enter the cerebral circulation (Biancardi et al. 2014) thus activating $\mathrm{AT}_{1}$ receptor on perivascular macrophages (PVM) in the brain, which promotes pathogenic actions of the PVM to instigate neurovascular dysfunction through reactive oxygen species (ROS) production via the superoxide-producing enzyme $\mathrm{NOX}_{2}$ during chronic hypertension (Faraco et al. 2016).

On a reciprocal basis, autonomic nervous system (SNA) also innervates bone marrow (Katayama et al. 2006) and spleen (Carnevale et al. 2016) what can stimulate mobilization and release of hematopoietic stem cells into blood stream through adrenergic neurotransmission stimulation (Hanoun et al. 2015; Santisteban et al. 2016). Sympathetic stimulation of bone marrow has been shown to favor enhanced proinflammatory responses in a mature innate immune system (Harwani et al. 2012). Likewise, selective ablation of splenic nerve prevents $\mathrm{T}$ cell egression from spleen and infiltration into renal and aorta tissue, and protects against hypertension (Carnevale et al. 2016). This interplay between sympathetic drive and immune cell stimulation can contribute to a positive feedback loop allowing further sympathetic stimulation and, ultimately, BP increase over time. However, increased sympathetic drive is a common finding in individuals with hypertension already stablished and, again, raises the question of whether hypertensionrelated inflammation is cause or consequence of high BP. For instance, renal sympathetic denervation inhibits myeloid cell activation and blood pressure in experimental models in a pressure-independent way (Xiao et al. 2015) as well as in human hypertensive patients (Zaldivia et al. 2017). However, the clinical studies could not discriminate between direct and indirect outcomes from renal denervation regarding direct nerve ablation effects on blood pressure versus indirect attenuation of innate immunity effect on other sympathetic beds resulting in reduced blood pressure.

The CNS has its own hand of innate immune cells which is the microglia (Kettenmann et al. 2011). Its role in SAH development has been demonstrated by a study in which selective ablation of microglia reduces glutamate, an excitatory neurotransmitter, receptor expression in PVN neurons as well as the plasma levels do vasopressin, and kidney norepinephrine concentrations (Shen et al. 2015). These findings indicate that neuronal excitation of hypothalamic pathways involved with sympathetic (parvocellular cells in PVN) and hydric (vasopressin secretion) control is under influence of local innate immune system within the CNS which contribute to high BP development.
Yet, the fact that kidney norepinephrine concentrations are diminished in microglia-depleted animals indicate that sympathetic-mediated changes in renal function are also affected by local inflammation within the CNS. Further studies have showed that not only sympathetic-driven increase in BP was mitigated by microglia inhibition but also peripheral inflammation was decreased (Carnevale et al. 2016; Santisteban et al. 2015; Shi et al. 2010) suggesting that central inflammation can influence peripheral inflammation as well.

The relation between sodium-dependent hypertension with disturbances in the immune system has been proposed since the 1960s (White and Grollman 1964) and reinforced a decade later (Svendsen 1976). Even though most studies confirm a dominant role of CD8 cells in hypertensive mechanisms that involve kidney and angiotensinergic mechanisms, CD4 cells also seem to play an important role in the development of sodium-dependent hypertension. $\mathrm{T}_{\mathrm{H}}$ cells seem particularly susceptible to stimulation by sodium. High concentrations of sodium can induce a $T_{H} 17$ polarization of naïve cells, both from humans and mice, through a mechanism mediated by the induction of serum glucorticoid kinase-1 (SGK1), essential to stabilization of the $\mathrm{T}_{\mathrm{H}} 17$ phenotype via IL-23 (Kleinewietfeld et al. 2013; Wu et al. 2013). In vitro studies showed that high-salt treatment also increased the production of pro-inflammatory cytokines like tumor necrosis factor alpha (TNF- $\alpha$ ), IL-2 and granulocyte-macrophage colony-stimulating factor by $\mathrm{T}_{\mathrm{H}} 17$ cells (Kleinewietfeld et al. 2013). Also, incubation of bone marrow-derived macrophages with $\mathrm{NaCl}$ elicited a strong pro-inflammatory phenotype characterized by enhanced proinflammatory cytokine production, increased expression of immune-stimulatory molecules, and an antigen-independent boost of $\mathrm{T}$ cell proliferation through pathways that may involve NF- $\mathrm{\kappa B}$ and MAPK signaling (Hucke et al. 2016). Other study reported that an $1 / 3$ increase in medium sodium concentration significantly induced IL- 6 and MCP-1 production by ARPE-19 cells (retinal pigment epithelium cells) and that the effect was not mediated by osmolarity since mannitol addition to the medium had no effect on IL-6 or MCP-1 production (Zhang et al. 2015a). Together, the findings indicate that high-sodium concentrations in the medium has the ability of direct stimulating inflammatory cells to produced cytokines. Outside the controlled conditions of in vitro experiments, a study carried out with humans showed that a high-salt meal is accompanied by a modest increase $(\sim 1.4 \%)$ in systemic serum sodium concentration at least for $2 \mathrm{~h}$ after the meal but no change was detected in serum concentration of classical hormones involved with body fluid homeostasis or endothelial function as endothelin-1 (ET-1), vasopressin (AVP) and atrial natriuretic peptide (ANP) (Dickinson et al. 2014). Since sodium absorption by the intestine does not distribute throughout body volume at 
once, such increase in serum sodium levels might indicate that inflammatory cells at some organs, like the intestine, could be under much greater sodium influence than other systemic inflammatory cells and, therefore, they could be more susceptible to sodium-driven changes in phenotype and cytokines profile production as describe in in vitro studies.

Besides the direct effect of sodium on lymphocytes differentiation, an indirect effect of salty diets on $\mathrm{T}_{\mathrm{H}} 17$ cells differentiation has also been explored and documented. Compelling evidence has indicated that high-salt diet intake can elicit significant changes in the population diversity of the intestinal microbiome. Studies by Wilck et al. (2017) have shown that a $4 \% \mathrm{NaCl}$ diet (8-10 times the recommended for rodents) for 14 days caused a reduction in the Lactobacillus murinus population of mice intestinal microbiota (Wilck et al. 2017). Such change in intestinal microbiota of high-salt diet-fed mice was accompanied by increased levels of blood pressure and increased population of CD4 $\mathrm{T}_{\mathrm{H}} 17$ pro-inflammatory cells in the intestinal mucosa (Wilck et al. 2017). When placed under a regular-salt diet, the intestinal population of Lactobacillus murinus returned to normal levels, clearly indicating that a high-salt diet can influence the bacterial population present in the intestine. In vitro assays confirmed that high-sodium concentration in the media inhibits the L. murinus growth (Wilck et al. 2017). "Treatment" of mice fed high-salt diet with L. murinus by gavage for 3 weeks reverted the effect of the diet on the levels of systolic and diastolic blood pressure (Wilck et al. 2017). Other studies also showed salt-induced increase in taxa from the Erwinia genus, the Christensenellaceae and Corynebacteriaceae families in Dahl salt-sensitive rats (Bier et al. 2018). In contrast, taxa from the Anaerostipes genus displayed a decreased abundance in this model (Bier et al. 2018) indicating that beyond Lactobacillus genus, the dysbiosis of other genus and families may also be implicated in salt-induced hypertension. Corroborating experimental data, a recent study identified a dysbiosis of the intestinal microbiota in hypertensive subjects, featured by reduced biodiversity and distinct bacterial signatures compared with the normotensive counterpart (Silveira-Nunes et al. 2020). Along with a reduction in Bacteroidetes members, hypertensive individuals displayed increased proportions of Lactobacillus and Akkermansia and decreased relative abundances Roseburia and Faecalibacterium within the Lachnospiraceae and Ruminococcaceae families (Silveira-Nunes et al. 2020). This study also reported an inflamed immune profile in hypertensive individuals with an increase in TNF/ IFN- $\gamma$ ratio, and in TNF and IL-6 production when compared to normotensive subjects (Silveira-Nunes et al. 2020). Despite lending support for experimental data, this study did not address important questions like whether the changes in gut microbiota are, indeed, a cause for the immune-related hypertension in humans or if dietary salt consumption is associated to the reported changes in microbiota. Experimental evidences indicate that high-sodium intake increase (and in some cases, nearly double) fecal sodium content of rats (Linz et al. 2012; Pácha 1998) and support the idea that high-sodium content in the feces are, somehow, related to bacterial dysbiosis, favoring relative abundance of some populations and disfavoring others.

Adding up the spectrum of possible mechanisms by which high-sodium diet can lead to inflammation-mediated hypertension, high-salt intake significantly enhanced ischemic brain damage which was associated with enhanced blood-brain-barrier disruption, increased leukocytes infiltration and loss of tight junction proteins expression without apparent change in blood pressure levels (Zhang et al. $2015 b)$. The authors also showed, by in vitro assays, that sodium chloride down-regulated protein expression by endothelial cells and substantially increased blood-brainbarrier permeability during starvation (Zhang et al. 2015b). Interesting, the authors also reported a positive correlation between urinary sodium levels and ischemic lesion size in stroke patients (Zhang et al. 2015b), indicating that blood-brain-barrier disruption by high-sodium intake can occur in humans as well. The mechanisms involved in this process are not yet fully understood but, some evidences suggest that it may involve inflammatory process triggered by IL-17 (Kleinewietfeld et al. 2013). Disruptions in blood-brain barrier have also been associated to high blood pressure (González-Marrero et al. 2012; Mueller and Heistad 1980) and in some cases, like the Ang II-induced high blood pressure, disruptions are reported to precede hypertension development (Capone et al. 2011) in experimental models. Capillary permeability of brain regions classically associated to sympathetic drive and blood pressure control like PVN, nucleus of the solitary tract (NTS) and RVLM are increased in hypertensive SHR but normal in pre-hypertensive SHR (Buttler et al. 2017). In addition, high circulating levels of Ang II can also produce disruptions of blood-brain barrier, what can facilitate not only the trafficking of small peptide into the brain parenchyma but also the infiltration of inflammatory cells from the circulation. Therefore, one may speculate that lesions across the blood-brain barrier has the potential to produce inflammation within the brain in a positive feedback fashion and consequently further activate neurogenic mechanisms involved with hypertension development. The injury process in vascular tissue stimulates infiltration of inflammatory cells into the brain, especially in the perivascular tissue (Yu et al. 2010), reinforcing the inflammatory process. Those cells are responsible for secreting other pro-inflammatory cytokines such as IL-6, IL-1 $\beta$ and TNF- $\alpha$ locally (Hashmat et al. 2016; Winklewski et al. 2015) thus affecting local neurotransmission and neuronal activity of cardioregulatory centers in the brain resulting in increased blood pressure. Some of the findings allow 
an interpretation in which blood-brain barrier disruptions may develop as a consequence of hypertension, and in this scenario brain inflammation develops as a consequence of the hypertensive state. However, evidences supporting such conclusion seems weak, because most of the studies fail to demonstrate a clear temporal correlation showing that hypertension precedes blood-brain barrier disruption in other models of hypertension than Ang II-induce. In fact, most of the studies show disruption in blood-brain barrier after hypertension is already stablished making it difficult to settle down a cause-consequence relation between blood-brain barriers disruptions, inflammation, and hypertension with current available knowledge.

Cytokines play an important role in the development, maintenance, and resolution of inflammatory processes, but here, we will draw the reader's attention to the pieces of evidence that support their role in the development of hypertension. As reported by Wang et al. (2012), some clinical findings support the role of $\mathrm{T}_{\mathrm{H}} 17 / \mathrm{IL}-17$ in the development of essential hypertension in humans as a positive correlation was found between hypertensive and nonhypertensive groups and $\mathrm{T}_{\mathrm{H}} 17$ cells count in the peripheral blood (Wang et al. 2012). Experimental data also showed that high-sodium intake was accompanied by an increase in IL-17A and BP of mice and that treatment of these mice with $L$. murinus reduced IL-17 and BP back to normal levels (Wilck et al. 2017). These findings indicate that IL-17 and BP levels are related to salt-drive changes in the intestinal microbiota and suggest that IL-17 might be related to hypertension development due to high-salt intake. Other findings also indicate that IL-17 may be associated with hypertension development, because knockout mice for IL-17 does not sustain hypertension produced by chronic infusion of Ang II (Madhur et al. 2010). The authors suggest that endothelial dysfunction caused by enhanced superoxide production in the vasculature is the most likely molecular mechanism involved in this process (Madhur et al. 2010). On the other hand, some clinical evidences indicate that neither IL17-producing cells (Youn et al. 2013) nor circulating IL-17 levels (Alhusseiny and Al-Nimer 2016) are positively correlated with increased levels of blood pressure. One caveat here is that most of the clinical studies searching a correlation between IL-17 and SAH were carried out in patients with stablished SAH, many under pharmacological treatment and regardless of salt-intake control or assessment. Since IL-17 seems to play an important role in experimental forms of salt-dependent hypertension, further studies in humans should be done to correctly assess the salt-intake role on IL-17 and BP correlation since most of the eastern society is actually on constant high-salt diet (Rodrigues et al. 2015). The controversial findings regarding the IL-17 role in hypertension evince the complexity of its action and reveal the need for further detailed studies including time course of the increase in blood vs. tissue IL-17 levels.

Similarly to IL-17, other cytokines are shown to play a role in hypertension development/maintenance either peripherally or at the central nervous system. For instance, tissue levels of IL-1 $\beta$, IL- 6 , and TNF- $\alpha$ were increased in the PVN of Ang II-induced hypertensive rats and intracerebroventricular administration of minocycline produced neuroprotective effects, with attenuation of mean arterial pressure, cardiac hypertrophy, plasma norepinephrine levels, decreased numbers of activated microglia and decreased mRNA expression for interleukin IL-1 $\beta$, IL- 6 , and TNF- $\alpha$ in PVN (Shi et al. 2010). In addition, both intracerebroventricular and PVN injections of IL-1 $\beta$ produced an increase in blood pressure of normotensive Sprague-Dawley rats (Shi et al. 2010). IL-1 $\beta$ is an interleukin produced by the innate immune system like monocytes and macrophages cells (Lopez-Castejon and Brough 2011) and is a key modulator of inflammatory responses (Knoll et al. 2017). The actions of IL-1 $\beta$ on SAH development seems to be focused on the central nervous system, influencing sympathetic drive by indirect mechanisms that involve activation of perivascular macrophages and increase of type 2 cyclooxygenase (COX2) expression/activity thus leading to increased production of prostaglandin $\mathrm{E}_{2}\left(\mathrm{PGE}_{2}\right)$ (Yu et al. 2010). Increased secretion of $\mathrm{PGE}_{2}$ by perivascular macrophages is believed to act on neuronal pathways within the PVN to increase the sympathetic drive to cardiovascular organs such as the heart and vasculature (Yu et al. 2010). IL-1 $\beta$ can also act on the endothelial cells of fenestrated capillaries in the brain to trigger sickness responses dependent on intact IL- $1 \beta$ signaling in blood vessels (Knoll et al. 2017). Since fenestrated capillaries are commonly found in circumventricular organs of the brain (CVO) such as the SFO and OVLT, it might be possible that CVO-acting IL- $1 \beta$ also contribute to activation of neurons in the lamina terminalis, especially at endothelial cells of fenestrated capillaries at CVO (Fig. 1). Evidence in the literature suggests that these mechanisms could be associated to those activated by Ang II, reinforcing pressor effect of this peptide on these specific sites.

At the central nervous system, TNF- $\alpha$ seems to act through similar mechanisms than IL- $1 \beta$, regulating the $\mathrm{PGE}_{2}$ production in perivascular macrophage and stimulating neuronal activation through molecular mechanisms activated by $\mathrm{PGE}_{2}$, especially in the PVN of Dahl salt-sensitive rats (Jiang et al. 2018). Experimental evidences have shown that intracarotid infusion of TNF- $\alpha$ produced an increase in renal sympathetic nerve activity as well as BP and heart rate in normotensive Sprague-Dawley rats (Yu et al. 2010). Yet, intracerebroventricular infusion of TACE, an enzyme that frees membrane attached TNF- $\alpha$, produced an increase in $\mathrm{BP}$ and sympathetic nerve activity of normotensive rats ( $\mathrm{Yu}$ et al. 2019), and an increase in BP levels with potentiation 
of the central pressor effects of Ang II in rats with chronic heart failure (Zera et al. 2009). These findings indicate that sympathetic drive can be influenced by brain-acting TNF- $\alpha$ at important sites that integrate osmotic/sodium-activated mechanisms such as the PVN and SFO (Fig. 1). Consistently, central blockade of TNF- $\alpha$ prevents dysregulation of brain RAS components and attenuates Ang II-induced hypertension (Sriramula et al. 2013) in rats, reinforcing the idea that centrally acting TNF- $\alpha$ play an important role linking inflammation to BP regulation through neurogenic mechanisms. Peripherally, especially in the kidneys, TNF- $\alpha$ has a dubious action on sodium handling. Experimental evidences showed that TNF- $\alpha$ can produce either increased sodium excretion or increased sodium retention and that those effects seem to depend on TNF- $\alpha$ levels, time of exposure and direct or indirect actions of TNF- $\alpha$ on nephron [reviewed in (Ramseyer and Garvin 2013)]. In summary, direct actions of TNF- $\alpha$ on TNF- $\alpha$ receptors of epithelial cells at the proximal tubule, thick ascending limb and collecting duct reduced sodium absorption, thus leading to an increase in sodium excretion (Ramseyer and Garvin 2013). On the other hand, more moderate and chronic activation of the adaptive immune response with participation of macrophages and lymphocytes by TNF- $\alpha$ might contribute to slowly developing renal damage what leads to increased $\mathrm{NaCl}$ retention due to loss of renal tissue ability to handle sodium (Ramseyer and Garvin 2013). In the last case, renal damage secondary to inflammation can contribute to development of hypertension with sodium retention, opposing the direct effects of TNF- $\alpha$ on nephron cells.

IL-6 is reported as one of the most consistently elevated cytokine related to human hypertension (Afsar et al. 2018; Sesso et al. 2007). For instance, hypertensive patients have higher baseline IL-6 levels when compared to normotensive ones on both diets, low sodium and high sodium (Chamarthi et al. 2011). These results may indicate that IL-6 increase in hypertensive patients is not related to high-sodium intake and might suggest that IL-6 increase could be secondary to SAH. On the other hand, a high-salt diet induces an increase in kidney IL-6 levels and administration of IL-6 antibody attenuated hypertension, albuminuria, and renal injury of Dahl saltsensitive rats (Hashmat et al. 2016) suggesting that high-salt intake could have a causal relation to IL-6 increase, even if indirectly. The increase in IL-6 secretion is involved with renal inflammatory process and, consequently, with the pathogenesis of nephropathies (Barbaro et al. 2017; Shahi et al. 2016) which can influence the development or maintenance of SAH by kidney-mediated mechanisms (Ruiz-Ortega et al. 2002). In a study carried out with patients who developed kidney injury, an increase in the expression of IL-6 was associated to an inflammatory process in the renal tubules and glomeruli, in addition to tubular hypertrophy (Fukatsu et al. 1991, 1993). Sodium reabsorption process in the distal tubules is carried out by $\mathrm{ENaC}$ and studies carried out by $\mathrm{Li}$ and cols. showed that IL-6 stimulates $\beta$-ENaC and $\gamma$-ENaC subunits expression in mouse cortical collecting duct cells ( $\mathrm{Li}$ et al. 2010) suggesting that higher rates of IL-6 production may facilitate greater sodium reabsorption by the kidney and sodium retention in the body, thus contributing to SAH development. If the similar mechanism occurs in $\mathrm{ChP}$, it could provide a link between the effects produced by high-sodium intake, increased circulating IL-6, and increased CSF sodium concentration since increased $\mathrm{ENaC}$ expression was also reported in ChP of Liddle's syndrome rats (Huysse et al. 2012; Wang and Leenen 2002).

Put under perspective, data in literature so far indicate that high-salt intake can modify the diversity of intestinal microbiome what triggers a chain of events that include increased intestinal population of $\mathrm{T}_{\mathrm{H}} 17$ cells, increased production of IL-17 and other cytokines such as IL- $1 \beta$ and TNF- $\alpha$ which, in turn, affect sodium handling by the kidney and the activity of hypothalamic nuclei that lead to increased sympathetic drive and blood pressure levels. However, one caveat here should be taken in consideration. Long-lasting exposure to high-salt diets equivalent to that humans currently ingest, i.e., about three times the recommendation by World Health Organization (WHO), from weaning to adult life in experimental models are not accompanied by increased sodium levels in the blood (Gomes et al. 2017). Therefore, the role of renalmediated changes in sodium metabolism in early stages of sodium-dependent hypertension should be taken carefully, because immune-related changes in renal function might not have the same impact on blood pressure as in late stages, when renal damage due to high-blood pressure could play a major role in hypertension maintenance. For the time being, many aspects and details of such mechanisms remain unclear, mostly because some effects of the cytokines in key sites of the brain are not fully understood. For instance, it is currently not known whether or not an increase in circulating levels of IL-6 can affect the $\mathrm{ENaC}$ expression in the choroid plexus or if IL-6 would be related in any way to increased levels of sodium in de CSF of high-salt-fed rats as a potential neurogenic mediated contribution of the IL- 6 to sodium-dependent hypertension. Taking together, the pieces of evidence indicate that proinflammatory cytokines stimulate cardioregulatory center in the brain to produce a neurogenic-mediated increase in blood pressure suggesting that brain inflammation may be an important factor leading to hypertension. On the other hand, studies have not addressed the question whether brain cytokines increase before hypertension develops in experimental models and in hypertensive patients. However, the mechanistic paradigm of inflammation-mediated hypertension, independent of cause for increased blood pressure or aggravation due to hypertension, opens a whole set of possible targets for antihypertensive drug therapy. 


\section{Propolis and its anti-inflammatory actions: possible application on inflammation-related hypertensive mechanisms}

Propolis, a word coming from the Greek "pro" meaning in favor of plus "polis" meaning city, is generally defined as a resinous substance produced by honeybees (Apis mellifera) in a process that involves harvesting resin from the local flora and alter it by blending this resinous substance with their salivary secretions and wax flakes secreted from special glands on their abdomens (Farooqui and Farooqui 2010). Propolis has defensive purposes in the hive protecting it against scratch cards, invasion by predators, and maintaining the internal temperature of the hive (De Vecchi and Drago 2007). The color, flavor, aroma, and chemical composition of propolis vary according to phenological factors, such as flora, geographical origin, seasonality of collection and production (Park et al. 2002; Teixeira et al. 2010). These factors can influence the biosynthesis of secondary metabolites produced by the plants (Teixeira et al. 2010) which, in turn, influences the qualitative and quantitative characteristics of the bioactive substances present in the resin used by bees to produce propolis. General composition of propolis comprises $50 \%$ resin, $30 \%$ bee-wax, $10 \%$ essential aromatic oils, 5\% bee-pollen, and 5\% other substances that include minerals as nicotinic acid and folic acid and vitamins A, B1, B2, B6, C, D, E (Bankova 2005). Propolis characterization and composition studies describe between 250 and 350 constituents, what depends on several factors as describe before (Huang et al. 2014). Flavonoids, phenolic acids and terpenes were identified as the major bioactive constituents of propolis and were extensively revised by Farooqui and Farooqui (2010). Based on color characteristics, propolis can be classified as brown, red, yellow and green (Machado et al. 2016).

Green propolis is one of the most studied, characterized and widely used in the medicine for its therapeutic properties (Kubota et al. 2004; Kujumgiev et al. 1999). Its deep green color results from the most important botanical source of resin used by the bees, the plant Baccharis dracunculifolia (Park et al. 2002, 2004). This plant belongs to the Asteraceae family and is native to southeastern part of Brazil (Park et al. 2004). Green propolis has approximately 78 bioactive compounds that include phenylpropanoids, triterpenes, sesquiterpenes, diterpenes, and flavonoids among other phenolic compounds (Chang et al. 2008; Park et al. 2002). Various biological and physiological activities have been attributed to green propolis, such as antibacterial (Drago et al. 2000), antiviral (Kujumgiev et al. 1999), anti-inflammatory (Szliszka et al. 2013; Tanaka et al. 2012), and anticancer (Scheller et al. 1989) effects. The main compounds associated to propolis anti-inflammatory effects are isosakuranetina (Cruz et al. 2016), caffeoylquinic acid (Abdel Motaal et al. 2016), kaempferol (Kitamura et al. 2018) and $p$-coumaric acids derivatives, including artepillin $\mathrm{C}$ (Paulino et al. 2008) (Table 1). Phenolic compounds are the most common bioactive substances present in a number of natural products extracts and frequently associated with therapeutic properties. One of these phenolic compounds is the kaempferol which is present in green propolis and has anti-inflammatory properties (Kitamura et al. 2018). In vivo and in vitro studies have shown that both, ethanolic extract of green propolis and kaempferol, were effective in reducing the population of type M1 macrophages through a mechanism that involves transdifferentiation of macrophages into $\mathrm{Gr}-1^{+}$myeloid-derived suppressor cells (MDSC) in visceral adipose tissue of obese mice (Kitamura et al. 2018). Since type M1 macrophages secrete important pro-inflammatory cytokines like TNF- $\alpha$ and IL-6 (Vogel et al. 2014), the propolis/kaempferol-induced transdifferentiation of M1 into MDSC, which have strong anti-inflammatory action, would represent important therapeutic properties by shifting the inflammatory process toward resolution. The cardiovascular benefits of the propolis/kaempferol action on inflammation remain to be further studied.

Despite the numerous biological properties of phenolic compounds like anti-inflammatory and anti-hypertensive, the most abundant bioactive compound found in propolis is artepillin $\mathrm{C}$, an important derivative of the $p$-coumaric acids. $P$-cumaric derivative compounds include drupanin, baccharin (Shimizu and Suzuki 2019), capsaicin (Zhang et al. 2019) and allyl isothiocyanate (Chang et al. 2019) that also have anti-inflammatory properties reported in the literature (Table 1). In vitro studies by Okamoto et al. (2012) showed that ethanolic extract of green propolis containing approximately $12 \%(\mathrm{w} / \mathrm{w})$ of artepillin C successfully inhibits the differentiation of cultures splenocytes into $\mathrm{T}_{\mathrm{H}} 17$ lymphocytes by approximately $92 \%$ when the culture was stimulated with IL-6 and TNF- $\alpha$ (Okamoto et al. 2012). The proposed mechanism behind this effect seems to involve the decrease in the IL- 6 and TNF- $\alpha$-dependent phosphorylation levels of signal transducers and activators of transcription (STAT3) (Okamoto et al. 2012). In vivo data also showed that differentiation of splenocytes cells into IL-17- producing cells in a model of collagen-induced arthritis mice fed propolis were significantly decreased (Tanaka et al. 2012) suggesting that in vitro effects of green propolis can be replicated in vivo. Besides its effects on $\mathrm{T}_{\mathrm{H}} 17$ cells differentiation, in vitro studies also showed that IL-17 production is reduced in a dose-dependent manner when cultured splenocytes of normal mice were stimulated with PMA and ionomycin (Tanaka et al. 2012). In addition to these findings, 
Table 1 Major components of green propolis and its actions related to hypertension and inflammation<smiles>COc1ccc([C@H]2CC(=O)c3c(O)cc(O)cc3O2)cc1</smiles>

Kaempferol<smiles>O=c1c(O)c(-c2ccc(O)cc2)oc2cc(O)cc(O)c12</smiles>

Caffeoylquinic acid<smiles>O=C(/C=C/C1CCCCC1)O[C@]1(C(=O)O)C[C@H](O)[C@H](O)[C@H](O)C1</smiles>

Artepillin C<smiles>CC(C)=CCc1cc(C=CC(=O)O)cc(CC=C(C)C)c1O</smiles>

p-Coumaric acid<smiles>O=C(O)/C=C/c1ccc(O)cc1</smiles>

Drupanin<smiles>CC(C)=CCc1cc(/C=C/C(=O)O)ccc1O</smiles>

Baccharin<smiles>CC(C)=CCc1cc(/C=C/C(=O)O)ccc1OC(=O)CCc1ccccc1</smiles>

Capsaicin<smiles>COc1cc(CNC(=O)CCCC/C=C/C(C)C)ccc1O</smiles>

Allyl-isothiocyanate (AITC)<smiles>C=CCN=C=S</smiles>

Key actions

Reduction of systolic blood pressure by vasodilation

Apoptosis induction by mutations in the genes that initiate the inflammatory process

Immunosuppression, hypotension associated to vasodilatory effects on the aorta

Hypotensive effects produced by vasodilation Anti-inflammatory action, regulation of TNF- $\alpha$ secretio

Inhibition of calcium transposition through the cell membrane of vascular smooth muscle

Reduction of nitric oxide

Anti-inflammatory effects associated to reduction of the inflammatory infiltrate, decrease in the prostaglandins production, inhibition of nitric oxide, modulation of $\mathrm{NF}_{-\mathrm{k}} \mathrm{B}$

Anti-inflammatory effect by reduction of IL-1 $\beta$, IL-6, IL-17, TNF- $\alpha$ and superoxide production in ischemic renal tissue

Anti-inflammatory effect by reduction of IL-6, IL-17 and TNF- $\alpha$ production by macrophages and murine splenocytes

Anti-inflammatory effect by reduction of IL-6, IL-17 and TNF- $\alpha$ production by macrophages and murine splenocytes

TNF- $\alpha$ release inhibition

Antioxidant properties by reduction of the oxidative stress

IL-6 and TNF- $\alpha$ release inhibition $\mathrm{NF}-\kappa \mathrm{B}$ inhibition
References

Maruyama et al. (2009, Spigoni et al. (2017)

Duarte et al. (1993), Kitamura et al. (2018)

Cicala et al. (2003), dos Santos et al. (2010), Mishima et al. (2005)

Paulino et al. (2008)

Mozaffari Godarzi et al. (2019), Shimizu and Suzuki (2019)

Shimizu and Suzuki (2019)

Shimizu and Suzuki (2019)

Antunes et al. (2019), Zhang et al. (2019)

Chang et al. (2019), Li et al. (2019)

${ }^{\text {a }}$ Structures reproduced in the Software ACD/Labs (version D05E41) 
other in vitro studies have also reported that green propolis reduces the production of IL- 6 , TNF- $\alpha$, and IL- $1 \beta$ but not IL-17 by J744A.1 macrophages stimulated with lipopolysaccharide (LPS) and interferon-gamma (INF- $\gamma$ ) (Szliszka et al. 2013). Such finding rises the possibility of green propolis components act on specific targets in cytokines producing cells and the nature of the stimulus can differentially affect the range of interleukins produced by macrophages. As discussed before, $\mathrm{T}_{\mathrm{H}} 17$ lymphocytes and IL-17, IL-6, TNF- $\alpha$, and IL- $1 \beta$ play an important role in salt-dependent hypertension what support the hypothesis that green propolis could be an effective anti-hypertensive agent for this type of hypertension, especially by targeting inflammatory mechanisms affected by artepillin $\mathrm{C}$.

In addition to its effects on interleukins production, green propolis can also directly inhibit the production of the inflammatory mediator $\mathrm{PGE}_{2}$ in vivo through its major bioactive compound, artepillin C (Paulino et al. 2008). In this study, mice with acute carrageenan-induced inflammatory reactions in the peritoneal cavity were treated with artepillin $\mathrm{C}$ and the levels of $\mathrm{PGE}_{2}$ were measured in the peritoneal fluid after $4 \mathrm{~h}$. The treatment was effective in reducing $\mathrm{PGE}_{2}$ levels to less than half of the untreated mice (Paulino et al. 2008). The author of this study proposed that the mechanism seems to involve the COX-2 downregulation as the levels of NF-kB-driven luciferase was reduced in HEK-293 cells treated with artepillin C (Paulino et al. 2008). As previously described in this review, $\mathrm{PGE}_{2}$ was demonstrated to activate neurons within the hypothalamus involved with sympathetic controlling pathways thus increasing the sympathetic drive to the cardiovascular system (Yu et al. 2010) and contributing to the hypertension. Therefore, it is reasonable to assume that propolis and artepillin $\mathrm{C}$ could have potential antihypertensive action through $\mathrm{PGE}_{2}$-mediated mechanisms.

Several pieces of evidence indicate that not only green propolis, but also isolated compounds present in the green propolis such as isosakuranetin (Maruyama et al. 2009) and caffeoylquinic acid (Mishima et al. 2005) have anti-hypertensive properties. Studies by Kubota et al. (2004) showed that a 4-week diet supplemented with green propolis $(0.5$ and $5.0 \% \mathrm{w} / \mathrm{w}$ ) reduced systolic blood pressure of SHR (Kubota et al. 2004). The proposed mechanism may involve acetylcholine (ACh)-induced vasodilation over vasoconstriction (Kubota et al. 2004). Aligned with these findings, studies by Mishima et al. (2005) found that water-ethanol extracts of green propolis and caffeoylquinic acid oral treatment of SHR for 28 days reduced high blood pressure, but not to levels (Mishima et al. 2005). However, results also showed that propolis prevented further increase in blood pressure compared to placebo-treated rats, but did not reduced BP below the levels measured at the beginning of treatment suggesting that green propolis might be preventing further disfunctions in BP regulatory mechanisms and not necessary reverting the ones already stablished. The authors hypothesized that anti-hypertensive effects may involve vasodilation, especially by caffeoylquinic acid (Mishima et al. 2005) based on studies showing vasodilator effect of prenethyl ester caffeic acid (CAPE) present in the European propolis (Cicala et al. 2003). The vasodilator effect of CAPE is said partially dependent on nitric oxide (NO) production by endothelium since contraction response to phenylephrine or $\mathrm{KCl}$ is still diminished by CAPE. Actually, CAPE vasorelaxant effect also occurs in absence of endothelium and it is likely due to an inhibitory effect on calcium movements through cell membranes of smooth muscle cells (Cicala et al. 2003).

Despite the importance of renal mechanisms controlling blood pressure, the effect of green propolis-based treatments on renal function have been assessed in very few studies. As one of the few examples, in a double-blind study conducted on patients with chronic kidney disease, oral treatment with green propolis extract had no effect on BP levels, but decreased proteinuria levels suggesting some improvement in damaged renal tissue and no change in glomerular filtration rate (Silveira et al. 2019). On the other hand, an experimental study carried out in Wistar rats undergoing renal ablation, oral treatment with red propolis extract lowered blood pressure, proteinuria, glomerulosclerosis and macrophage infiltration in kidney tissue (Teles et al. 2015). These conflicting findings can result from several differences in experimental design, model, reversibility of the renal damage, salt intake assessment as well as the stability of propolis components in the digestive system, bioavailability and dose. Findings in the literature clearly point out the role of inflammation in renal tissue as an important factor contributing to renal damage and SAH (Rucker et al. 2018). Therefore, it seems unlike that the anti-inflammatory properties of propolis could not provide any significant protection against renal inflammation and disfunctions unless the damage extends to far so its impact on BP could be reversed. Therefore, further studies must be conducted in order to better understand the mechanisms underlying some of the anti-hypertensive properties of propolis targeting the renal system. Working hypothesis for the anti-inflammatory and anti-hypertensive effects of green propolis summarized in Fig. 2.

Many of the findings discussed here suggests that green propolis has an important therapeutic potential to treat hypertension by acting on vascular, renal and neural mechanisms supporting SAH. The emerging role of inflammation at central and peripheral mechanisms controlling BP and its contribution for $\mathrm{SAH}$ rises the importance of stablishing the effects and mechanisms of anti-inflammatory therapies base on green propolis given its acknowledged anti-inflammatory property. Whether the use of green propolis-based medicine 

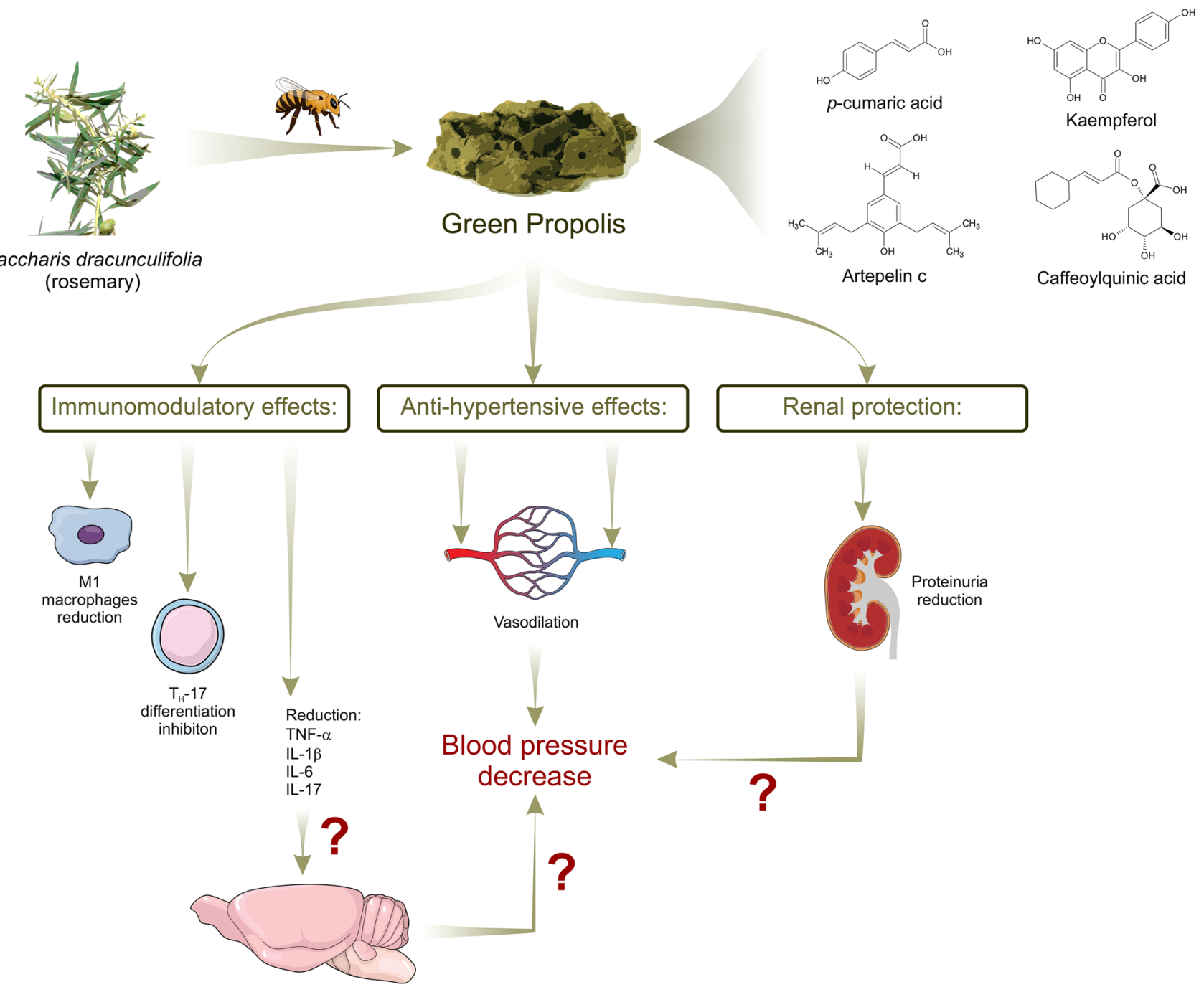

Fig. 2 Working hypothesis for the anti-inflammatory and anti-hypertensive effects of green propolis. Resinous material produced by Baccharis dracuncufolia (rosemary) is harvested and processed by honeybees to produce green propolis. This resinous and defensive material is composed of many bioactive compounds like $p$-cumaric, kaempferol, Artepelin C, Caffeoyliquinic acid, among others. These compounds can act on the immune system allowing the M1 macrophages reduction through a mechanism that involves the transdifferentiation of macrophages into Gr-1+myeloid-derived suppressor cells, inhibiting the differentiation of lymphocytes into $T_{H} 17$ and reducing production/release of inflammatory cytokines as TNF$\alpha$, IL-1 $\beta$, IL- 6 and IL-17 that might affect central nervous system

or supplements have better results if the use starts before or after SAH is already stablished has yet to be determined. However, data reported here suggest that green propolis might be effective in lower BP levels after SAH is stablished and, therefore, may represent an important adjuvant in $\mathrm{SAH}$ treatment through immunomodulatory mechanisms. mechanisms controlling sympathetic drive and blood pressure. Also, propolis compounds are demonstrated to act on vascular mechanisms leading to predominance of relaxing over contractile factors and supporting blood pressure reduction. Despite renal protection has been reported, it is not always accompanied by blood pressure reduction, suggesting that vascular and neural actions of the propolis bioactive compounds might be more important in the anti-hypertensive effects. However, most of the mechanisms involved in this process, if really involved in anti-hypertensive propertied of propolis, remain largely unknow. $I L-1 \beta$ interleukin $1 \beta, I L-6$ interleukin $6, I L-17$ interleukin 6 , $T N F-\alpha$ tumor necrosis factor- $\alpha, M 1$ macrophage M1, $T_{H} 17$ lymphocyte $\mathrm{T}$ helper 17

\section{Conclusion}

The contribution of the immune system to the development SAH represents a new paradigm and the interaction between immune system and neural mechanisms controlling blood pressure through the gut-brain axis opens up a wide variety of new possible targets for adjuvants in the hypertension therapy. However, many questions remain unanswered regarding the nature and time course of inflammatory 
mechanisms to the development of SAH, especially because some findings indicate that inflammation plays a primary role in SAH while other finding sustain a different role, i.e., immune system is a adjuvant in SAH maintenance since it also may appear after hypertension sets in. It is our view that the cause-consequence role of the inflammation on SAH development largely depends on the hypertension origin and other factors listed as risky for SAH development. At least for sodium-dependent forms of hypertension, evidences indicate that sodium-driven inflammation seems to play a pivotal primary role in adaptive changes that trigger neural and renal disfunctions related to hypertension (Fig. 1). Natural products like green propolis provide a rich corollary of bioactive components, many with anti-inflammatory properties, reaching multiple targets. This is one of the greatest advantages of natural products, because the diversity of active compounds can collectively act on different pathophysiological mechanisms, especially important in a multifactorial disease like hypertension. However, many mechanistic aspects of the effect of green propolis on BP control have yet to be elucidated and further studies are needed to accurately establish the relationship between propolis, immune system, gut microbiota and BP control, and the benefits and risks of green propolis therapies for human cardiovascular health. The multiple targets of modulation, including the immune system and local blood pressure control mechanisms, as well as the lack of additional knowledge of how the neural and humoral mechanisms of BP control are affected by green propolis, make it a suitable choice for future studies and development of new medicine for hypertension treatment.

\section{Perspectives}

The use of natural products to treat hypertension focusing on immune-mediated mechanisms seems promising and may yield several benefits as adjuvant therapy. More promising is the possibility of treatment of other immune co-morbidities that develop along with or are aggravated by hypertension. The recent outbreak of the new coronavirus infectious disease (COVID-19) have exposed a critical and concerning aspect of hypertension: pre-existing hypertension diagnose, independently of the treatment, seem to prompt the individual to a more severe form of the severe acute respiratory syndrome associated to coronavirus-2 (SARS-CoV-2) as many reports are showing (Fang et al. 2020; Strabelli and Uip 2020). Recent evidence has shown that comorbidities such as arterial hypertension can increase the risk of death due to complications associated to COVID-19 by 2.5 times (Lippi et al. 2020) and, therefore, understanding the relationship between hypertension and respiratory disorders associated with COVID-19 is important and urgent. The role of the immune system in the hypertension-SARS-CoV-2 interaction is still poorly understood. It is known that the inflammatory profile in COVID 19 has its own characteristics, such as an increase in the serum concentration of TNF$\alpha$, IL-6 and IL-10 (Diao et al. 2020; Huang et al. 2020), which are higher in patients under intensive care. Surprisingly, these levels of cytokines become negatively correlated with the counting of $\mathrm{T}$ cells over time, what has been associated to depletion and functional exhaustion of these cells (Diao et al. 2020). Other authors have also shown that, in addition to the depletion of CD4 INF- $\gamma^{+}$and TNF- $\alpha^{+}$cells, the population of $\mathrm{CD} 8$ granzyme $\mathrm{B}^{+}$and perforin ${ }^{+}$cells is increased in SARS-CoV-2 patients (Zheng et al. 2020), revealing an intricated immune response to the virus infection over time. Additionally, in a recent clinical study performed by Huang et al. (2020), the cytokine profile of intensive unit care and non-intensive unit care patients infected with the new coronavirus was assessed and revealed that most of the cytokines associated to hypertension such as IL-1 $\beta$, IL-6, IL-17, and TNF- $\alpha$ are, as expected, increased in those patients that developed symptoms more severe of the COVID-19 (Huang et al. 2020). What draw our attention in this study was a careful analysis of the IL-5, IL-6, IL-8 levels distribution of patients on intensive unit care that displayed distinct profiles, with several values extremely high and others with values extremely low (Huang et al. 2020) supplement material. The authors did not cross-reference the cytokines levels with hypertension/diabetes history of the patient, but one can wonder whether or not those with hypertension are the ones with higher levels of those cytokines and how this relationship could contribute to the severity of the pulmonary edema. Furthermore, the interaction between the immune responses elicited by the coronavirus infection and the sodium-dependent forms of hypertension are not stablished and may represent an important mechanism contributing to the higher probability of severe respiratory fail development reported in hypertensive patients infected by coronavirus. If such relation could be demonstrated, treatment with immune-modulatory properties medicines like the green propolis could show itself promising, producing beneficial effects on both, blood pressure control and SARSCoV improvement.

Acknowledgements The authors thank the Federal University of Ouro Preto (UFOP) and funding Brazilian agencies CAPES, FAPEMIG and CNPq.

Author contributions MACB: Literature review, drafted the manuscript, prepared figures, edited and revised manuscript, approved the final version of the manuscript. DCAB: Literature review, drafted the manuscript, prepared figures, edited and revised manuscript, approved the final version of the manuscript. SALM: Revised manuscript, approved the final version of the manuscript. GHBS: Revised manuscript, approved the final version of the manuscript. ODHS: Revised manuscript, approved the final version of the manuscript. LMC: Conception and design the study, prepared figures, drafted 
manuscript, edited and revised manuscript, approved final version of the manuscript.

Funding Minas Gerais State Research Foundation (FAPEMIG); Federal University of Ouro Preto, Higher Education Personnel Improvement Coordination (CAPES), National Council for Scientific and Technological Development (CNPq) and personal resources of the researchers.

\section{Compliance with ethical standards}

Conflict of interest None. For all the authors, there are no potential conflicts of interest.

\section{References}

Abais-Battad JM, Rudemiller NP, Mattson DL (2015) Hypertension and immunity: mechanisms of $\mathrm{T}$ cell activation and pathways of hypertension. Curr Opin Nephrol Hypertens 24:470-474. https ://doi.org/10.1097/MNH.0000000000000146

Abdel Motaal A, Ezzat SM, Tadros MG, El-Askary HI (2016) vivo anti-inflammatory activity of caffeoylquinic acid derivatives from Solidago virgaurea in rats. Pharm Biol 54:2864-2870. https:// doi.org/10.1080/13880209.2016.1190381

Adams JM, Madden CJ, Sved AF, Stocker SD (2007) Increased dietary salt enhances sympathoexcitatory and sympathoinhibitory responses from the rostral ventrolateral medulla. Hypertension 50:354-359. https://doi.org/10.1161/HYPERTENSIONAHA 107.091843

Afsar B et al (2018) Salt intake and immunity. Hypertension 72:19-23. https://doi.org/10.1161/hypertensionaha.118.11128

Alhusseiny A, Al-Nimer M (2016) Assessment of serum interleukins-17 and $1 \beta$ levels in hypertensive patients treated with angiotensin converting enzyme and/or angiotensin II receptor blockers Saudi. J Health Sci 5:125-129. https://doi.org/10.4103/22780521.195814

Alvarez Li FC, Espinosa Brito AD, Ordunez Garcia PO, Silva Aycaguer LC (1999) Risk markers and high blood pressure. The Cienfuegos global project. Longitudinal study 1992-1994. Revista de investigacion clinica organo del Hospital de Enfermedades de la Nutricion 51:151-158

Amin MS, Wang HW, Reza E, Whitman SC, Tuana BS, Leenen FH (2005) Distribution of epithelial sodium channels and mineralocorticoid receptors in cardiovascular regulatory centers in rat brain. Am J Physiol Regul Integr Comp Physiol 289:R1787R1797. https://doi.org/10.1152/ajpregu.00063.2005

Antunes MM et al (2019) Oral supplementation with capsaicin reduces oxidative stress and IL-33 on a food allergy murine model. World Allergy Organ J 12:100045. https://doi.org/10.1016/j.waojo u. 2019.100045

APA (2020) High blood pressure. Dalas

Bankova V (2005) Chemical diversity of propolis and the problem of standardization. J Ethnopharmacol 100:114-117. https://doi. org/10.1016/j.jep.2005.05.004

Barbaro NR et al (2017) Dendritic cell amiloride-sensitive channels mediate sodium-induced inflammation and hypertension. Cell Rep 21:1009-1020. https://doi.org/10.1016/j.celrep.2017.10.002

Bertog SC, Sobotka PA, Sievert H (2012) Renal denervation for hypertension. JACC Cardiovasc Interv 5:249-258. https://doi. org/10.1016/j.jcin.2011.12.011
Biancardi VC, Son SJ, Ahmadi S, Filosa JA, Stern JE (2014) Circulating angiotensin II gains access to the hypothalamus and brain stem during hypertension via breakdown of the blood-brain barrier. Hypertension 63:572-579. https://doi.org/10.1161/hyper tensionaha.113.01743

Bie P, Evans RG (2017) Normotension, hypertension and body fluid regulation: brain and kidney. Acta Physiol (Oxf) 219:288-304. https://doi.org/10.1111/apha.12718

Bier A, Braun T, Khasbab R, Di Segni A, Grossman E, Haberman Y, Leibowitz A (2018) A high salt diet modulates the gut microbiota and short chain fatty acids production in a salt-sensitive hypertension rat Model. Nutrients 10:1154. https://doi.org/10.3390/ nu10091154

Bouhanick B, Vaisse B, Schavgoulidze A, Gandia P (2019) Assessment for antihypertensive drug intake in France in 2019 and adherence. Presse Med 48:1520-1526. https://doi.org/10.1016/j. lpm.2019.08.009

Bourque CW (2008) Central mechanisms of osmosensation and systemic osmoregulation. Nat Rev Neurosci 9:519-531. https://doi. org/10.1038/nrn2400

Brown PD, Davies SL, Speake T, Millar ID (2004) Molecular mechanisms of cerebrospinal fluid production. Neuroscience 129:957970. https://doi.org/10.1016/j.neuroscience.2004.07.003

Buttler L, Jordão MT, Fragas MG, Ruggeri A, Ceroni A, Michelini LC (2017) Maintenance of blood-brain barrier integrity in hypertension: a novel benefit of exercise training for autonomic control. Front Physiol. https://doi.org/10.3389/fphys.2017.01048

Capone C, Faraco G, Park L, Cao X, Davisson RL, Iadecola C (2011) The cerebrovascular dysfunction induced by slow pressor doses of angiotensin II precedes the development of hypertension. Am J Physiol Heart Circ Physiol 300:H397-H407. https://doi. org/10.1152/ajpheart.00679.2010

Carey RM et al (2018) Resistant hypertension: detection, evaluation, and management: a scientific statement from the American Heart Association. Hypertension 72:e53-e90. https://doi.org/10.1161/ HYP.0000000000000084

Carnevale D et al (2016) A cholinergic-sympathetic pathway primes immunity in hypertension and mediates brain-to-spleen communication. Nat Commun 7:13035. https://doi.org/10.1038/ncomm s13035

Chamarthi B et al (2011) Inflammation and hypertension: the interplay of interleukin- 6 dietary sodium, and the renin-angiotensin system in humans. Am J Hypertens 24:1143-1148. https://doi. org/10.1038/ajh.2011.113

Chang R, Piló-Veloso D, Morais SAL, Nascimento EA (2008) Analysis of a Brazilian green propolis from Baccharis dracunculifolia by HPLC-APCI-MS and GC-MS \%. J Revista Brasileira de Farmacognosia 18:549-556

Chang WJ, Chen BH, Inbaraj BS, Chien JT (2019) Preparation of allyl isothiocyanate nanoparticles, their anti-inflammatory activity towards RAW 264.7 macrophage cells and anti-proliferative effect on HT1376 bladder cancer cells. J Sci Food Agric 99:3106-3116. https://doi.org/10.1002/jsfa.9524

Cicala C, Morello S, Iorio C, Capasso R, Borrelli F, Mascolo N (2003) Vascular effects of caffeic acid phenethyl ester (CAPE) on isolated rat thoracic aorta. Life Sci 73:73-80. https://doi. org/10.1016/s0024-3205(03)00235-2

Cowley AW, Roman RJ, Fenoy FJ, Mattson DL (1992) Effect of renal medullary circulation on arterial pressure. J Hypertens Suppl 10:S187-193

Cruz MP et al (2016) Antinoceptive and anti-inflammatory activities of the ethanolic extract, fractions and flavones isolated from Mimosa tenuiflora (Willd.) Poir (Leguminosae). PLoS ONE 11:e0150839. https://doi.org/10.1371/journal.pone.0150839 
Daugherty SL et al (2012) Incidence and prognosis of resistant hypertension in hypertensive patients. Circulation 125:1635-1642. https://doi.org/10.1161/CIRCULATIONAHA.111.068064

de Figueiredo-Rinhel ASG, de Andrade MF, Landi-Librandi AP, Azzolini A, Kabeya LM, Bastos JK, Lucisano-Valim YM (2019) Incorporation of Baccharis dracunculifolia DC (Asteraceae) leaf extract into phosphatidylcholine-cholesterol liposomes improves its anti-inflammatory effect in vivo. Nat Prod Res 33:2521-2525. https://doi.org/10.1080/14786419.2018.1448809

De Vecchi E, Drago L (2007) Propolis' antimicrobial activity: what's new? Infez Med 15:7-15

Diao B et al. (2020) Reduction and functional exhaustion of $\mathrm{T}$ cells in patients with coronavirus disease 2019 (COVID19). medRxiv:2020.2002.2018.20024364. https://doi. org/10.1101/2020.02.18.20024364

Dickinson KM, Clifton PM, Burrell LM, Barrett PHR, Keogh JB (2014) Postprandial effects of a high salt meal on serum sodium, arterial stiffness, markers of nitric oxide production and markers of endothelial function. Atherosclerosis 232:211-216. https://doi. org/10.1016/j.atherosclerosis.2013.10.032

dos Santos MD, Chen G, Almeida MC, Soares DM, de Souza GE, Lopes NP, Lantz RC (2010) Effects of caffeoylquinic acid derivatives and C-flavonoid from Lychnophora ericoides on in vitro inflammatory mediator production. Nat Prod Commun 5:733-740

Drago L, Mombelli B, De Vecchi E, Fassina MC, Tocalli L, Gismondo MR (2000) In vitro antimicrobial activity of propolis dry extract. J Chemother 12:390-395. https://doi.org/10.1179/ joc.2000.12.5.390

Duarte J, Perez Vizcaino F, Utrilla P, Jimenez J, Tamargo J, Zarzuelo A (1993) Vasodilatory effects of flavonoids in rat aortic smooth muscle. Structure-activity relationships. Gen Pharmacol 24:857862. https://doi.org/10.1016/0306-3623(93)90159-u

El Menyiy N, Al-Waili N, El Ghouizi A, Al-Waili W, Lyoussi B (2018) Evaluation of antiproteinuric and hepato-renal protective activities of propolis in paracetamol toxicity in rats. Nutr Res Pract 12:535-540. https://doi.org/10.4162/ nrp.2018.12.6.535

Esler M (2015) The sympathetic nervous system in hypertension: back to the future? Curr Hypertens Rep 17:11. https://doi.org/10.1007/ s11906-014-0519-8

Fang L, Karakiulakis G, Roth M (2020) Are patients with hypertension and diabetes mellitus at increased risk for COVID-19 infection? Lancet Respir Med 8:e21. https://doi.org/10.1016/S2213 $-2600(20) 30116-8$

Faraco $\mathrm{G}$ et al (2016) Perivascular macrophages mediate the neurovascular and cognitive dysfunction associated with hypertension. J Clin Investig 126:4674-4689. https://doi.org/10.1172/jci86950

Farooqui T, Farooqui A (2010) Molecular mechanism underlying the therapeutic activities of propolis: a critical review. Curr Nutr Food Sci 6:186-199

Fukatsu A, Matsuo S, Tamai H, Sakamoto N, Matsuda T, Hirano T (1991) Distribution of interleukin-6 in normal and diseased human kidney. Lab Invest 65:61-66

Fukatsu A, Matsuo S, Yuzawa Y, Miyai H, Futenma A, Kato K (1993) Expression of interleukin 6 and major histocompatibility complex molecules in tubular epithelial cells of diseased human kidneys. Lab Invest 69:58-67

Gomes PM et al (2017) Chronic high-sodium diet intake after weaning lead to neurogenic hypertension in adult Wistar rats. Sci Rep 7:5655. https://doi.org/10.1038/s41598-017-05984-9

González-Marrero I et al (2012) High blood pressure effects on the brain barriers and choroid plexus secretion. Neurosci Med 03:60-64. https://doi.org/10.4236/nm.2012.31009

Grillo A, Salvi L, Coruzzi P, Salvi P, Parati G (2019) Sodium intake and hypertension. Nutrients. https://doi.org/10.3390/nu11091970
Groppelli A, Giorgi DM, Omboni S, Parati G, Mancia G (1992) Persistent blood pressure increase induced by heavy smoking. J Hypertens 10:495-499. https://doi.org/10.1097/00004872-19920 5000-00014

Guyenet PG (2006) The sympathetic control of blood pressure. Nat Rev Neurosci 7:335-346

Guyton AC (1989) Roles of the kidneys and fluid volumes in arterial pressure regulation and hypertension. Chin J Physiol 32:49-57

Guyton AC (1991) Abnormal renal function and autoregulation in essential hypertension. Hypertension 18:III49-III53. https://doi. org/10.1161/01.hyp.18.5_suppl.iii49

Guyton AC, Coleman TG, Cowley AW, Scheel KW, Manning RD, Norman RA (1972) Arterial pressure regulation: overriding dominance of the kidneys in long-term regulation and in hypertension. Am J Med 52:584-594. https://doi.org/10.1016/00029343(72)90050-2

Guzik TJ et al (2007) Role of the T cell in the genesis of angiotensin II induced hypertension and vascular dysfunction. J Exp Med 204:2449-2460. https://doi.org/10.1084/jem.20070657

Hadi A, Pourmasoumi M, Ghaedi E, Sahebkar A (2019) The effect of curcumin/turmeric on blood pressure modulation: a systematic review and meta-analysis. Pharmacol Res 150:104505. https:// doi.org/10.1016/j.phrs.2019.104505

Hanoun M, Maryanovich M, Arnal-Estape A, Frenette PS (2015) Neural regulation of hematopoiesis, inflammation, and cancer. Neuron 86:360-373. https://doi.org/10.1016/j.neuron.2015.01.026

Harwani SC, Chapleau MW, Legge KL, Ballas ZK, Abboud FM (2012) Neurohormonal modulation of the innate immune system is proinflammatory in the prehypertensive spontaneously hypertensive rat, a genetic model of essential hypertension. Circ Res 111:1190-1197. https://doi.org/10.1161/CIRCRESAHA .112 .277475

Hashmat S, Rudemiller N, Lund H, Abais-Battad JM, Van Why S, Mattson DL (2016) Interleukin-6 inhibition attenuates hypertension and associated renal damage in Dahl salt-sensitive rats. Am J Physiol Renal Physiol 311:F555-F561. https://doi. org/10.1152/ajprenal.00594.2015

Haywood JR, Buggy J, Fink GD, DiBona GF, Johnson AK, Brody MJ (1984) Alterations in cerebrospinal fluid sodium and osmolality in rats during one-kidney, one-wrap renal hypertension. Clin Exp Pharmacol Physiol 11:545-549

Huang BS, Veerasingham SJ, Leenen FH (1998) Brain "ouabain," ANG II, and sympathoexcitation by chronic central sodium loading in rats. Am J Physiol 274:H1269-1276

Huang S, Zhang CP, Wang K, Li GQ, Hu FL (2014) Recent advances in the chemical composition of propolis. Molecules 19:19610 19632. https://doi.org/10.3390/molecules 191219610

Huang C et al (2020) Clinical features of patients infected with 2019 novel coronavirus in Wuhan, China. Lancet 395:497-506. https ://doi.org/10.1016/S0140-6736(20)30183-5

Hucke S et al (2016) Sodium chloride promotes pro-inflammatory macrophage polarization thereby aggravating CNS autoimmunity. J Autoimmun 67:90-101. https://doi.org/10.1016/j. jaut.2015.11.001

Huysse JW, Amin M, Yang B, Leenen FHH (2012a) Salt-induced hypertension in a mouse model of Liddle syndrome is mediated by epithelial sodium channels in the brain. Hypertension 60:691-696. https://doi.org/10.1161/HYPERTENSIONAHA .112 .193045

Itani HA et al (2016) Activation of human T cells in hypertension: studies of humanized mice and hypertensive humans. Hypertension 68:123-132. https://doi.org/10.1161/HYPERTENSI ONAHA.116.07237

Ivy JR, Bailey MA (2014) Pressure natriuresis and the renal control of arterial blood pressure. J Physiol 592:3955-3967. https:// doi.org/10.1113/jphysiol.2014.271676 
Jiang E et al (2018) Expression of proinflammatory cytokines is upregulated in the hypothalamic paraventricular nucleus of Dahl salt-sensitive hypertensive rats. Front Physiol 9:104. https ://doi.org/10.3389/fphys.2018.00104

Jörg S et al (2016) High salt drives Th17 responses in experimental autoimmune encephalomyelitis without impacting myeloid dendritic cells. Exp Neurol 279:212-222. https://doi. org/10.1016/j.expneurol.2016.03.010

Karimy JK et al (2017) Inflammation-dependent cerebrospinal fluid hypersecretion by the choroid plexus epithelium in posthemorrhagic hydrocephalus. Nat Med 23:997-1003. https://doi. org/10.1038/nm.4361

Karppanen H, Mervaala E (2006) Sodium intake and hypertension. Prog Cardiovasc Dis 49:59-75. https://doi.org/10.1016/j. pcad.2006.07.001

Katayama Y, Battista M, Kao WM, Hidalgo A, Peired AJ, Thomas SA, Frenette PS (2006) Signals from the sympathetic nervous system regulate hematopoietic stem cell egress from bone marrow. Cell 124:407-421. https://doi.org/10.1016/j. cell.2005.10.041

Kettenmann H, Hanisch U-K, Noda M, Verkhratsky A (2011) Physiology of microglia. Physiol Rev 91:461-553. https://doi. org/10.1152/physrev.00011.2010

King AJ, Osborn JW, Fink GD (2007) Splanchnic circulation is a critical neural target in angiotensin II salt hypertension in rats. Hypertension 50:547-556. https://doi.org/10.1161/HYPER TENSIONAHA.107.090696

Kitamura H, Saito N, Fujimoto J, Nakashima KI, Fujikura D (2018) Brazilian propolis ethanol extract and its component kaempferol induce myeloid-derived suppressor cells from macrophages of mice in vivo and in vitro. BMC Complement Altern Med 18:138. https://doi.org/10.1186/s12906-018-2198-5

Klahr S, Morrissey J (1998) Angiotensin II and gene expression in the kidney. Am J Kidney Dis 31:171-176. https://doi.org/10.1053/ ajkd.1998.v31.pm9428470

Kleinewietfeld M et al (2013) Sodium chloride drives autoimmune disease by the induction of pathogenic TH17 cells. Nature 496:518522. https://doi.org/10.1038/nature11868

Knoll JG, Krasnow SM, Marks DL (2017) Interleukin-1 $\beta$ signaling in fenestrated capillaries is sufficient to trigger sickness responses in mice. J Neuroinflamm 14:219. https://doi.org/10.1186/s1297 4-017-0990-7

Kubota Y et al (2004) Anti-hypertensive effects of Brazilian propolis in spontaneously hypertensive rats. Clin Exp Pharmacol Physiol 31(Suppl 2):S29-S30. https://doi.org/10.111 1/j.1440-1681.2004.04113.x

Kujumgiev A, Tsvetkova I, Serkedjieva Y, Bankova V, Christov R, Popov S (1999) Antibacterial, antifungal and antiviral activity of propolis of different geographic origin. J Ethnopharmacol 64:235-240. https://doi.org/10.1016/s0378-8741(98)00131-7

Kwon YI, Vattem DA, Shetty K (2006) Evaluation of clonal herbs of Lamiaceae species for management of diabetes and hypertension. Asia Pac J Clin Nutr 15:107-118

Leenen FH (2010) The central role of the brain aldosterone-"ouabain" pathway in salt-sensitive hypertension. Biochim Biophys Acta 1802:1132-1139. https://doi.org/10.1016/j.bbadis.2010.03.004

Leenen FH, Ruzicka M, Huang BS (2002) The brain and salt-sensitive hypertension. Curr Hypertens Rep 4:129-135

Leenen FHH, Hou X, Wang H, Ahmad M (2015) Enhanced expression of epithelial sodium channels causes salt induced hypertension in mice through inhibition of the 2 isoform of $\mathrm{Na}+\mathrm{K}+$ ATPase. Physiol Rep. https://doi.org/10.14814/phy2.12383

Li K, Guo D, Zhu H, Hering-Smith KS, Hamm LL, Ouyang J, Dong Y (2010) Interleukin-6 stimulates epithelial sodium channels in mouse cortical collecting duct cells. Am J Physiol Regul Integr
Comp Physiol 299:R590-R595. https://doi.org/10.1152/ajpre gu.00207.2009

Li CX et al (2019) Allyl isothiocyanate ameliorates lipid accumulation and inflammation in nonalcoholic fatty liver disease via the Sirt1/ AMPK and NF-kappaB signaling pathways. World J Gastroenterol 25:5120-5133. https://doi.org/10.3748/wjg.v25.i34.5120

Li Y, Wei B, Liu X, Shen XZ, Shi P (2020) Microglia, autonomic nervous system, immunity and hypertension: is there a link? Pharmacol Res 155:104451. https://doi.org/10.1016/j.phrs.2019.104451

Lima CT, Carvalho FM, Quadros Cde A, Goncalves HR, Silva Junior JA, Peres MF, Bonfim MS (1999) Arterial hypertension and alcoholism among workers in an oil refinery. Revista panamericana de salud publica Pan Am J Public Health 6:185-191. https://doi. org/10.1590/s1020-49891999000800006

Linz D et al (2012) Antihypertensive and laxative effects by pharmacological inhibition of sodium-proton-exchanger subtype 3-mediated sodium absorption in the gut. Hypertension 60:1560-1567. https://doi.org/10.1161/HYPERTENSIONAHA.112.201590

Lippi G, Wong J, Henry BM (2020) Hypertension and its severity or mortality in Coronavirus Disease 2019 (COVID-19): a pooled analysis. Pol Arch Intern Med. https://doi.org/10.20452 /pamw.15272

Lopez-Castejon G, Brough D (2011) Understanding the mechanism of IL-1beta secretion. Cytokine Growth Factor Rev 22:189-195. https://doi.org/10.1016/j.cytogfr.2011.10.001

Ma L-J et al (2011) Angiotensin type 1 receptor modulates macrophage polarization and renal injury in obesity. Am J Physiol Renal Physiol 300:F1203-F1213. https://doi.org/10.1152/ajpre nal.00468.2010

Machado CS et al (2016) Comparative study of chemical composition and biological activity of yellow green, brown, and red Brazilian propolis. Evid Based Complement Alternat Med 2016:6057650. https://doi.org/10.1155/2016/6057650

Madhur MS, Lob HE, McCann LA, Iwakura Y, Blinder Y, Guzik TJ, Harrison DG (2010) Interleukin 17 promotes angiotensin IIinduced hypertension and vascular dysfunction. Hypertension 55:500-507. https://doi.org/10.1161/HYPERTENSIONAHA 109.145094

Marques F, Sousa JC, Correia-Neves M, Oliveira P, Sousa N, Palha JA (2007) The choroid plexus response to peripheral inflammatory stimulus. Neuroscience 144:424-430. https://doi.org/10.1016/j. neuroscience.2006.09.029

Maruyama H, Sumitou Y, Sakamoto T, Araki Y, Hara H (2009) Antihypertensive effects of flavonoids isolated from Brazilian green propolis in spontaneously hypertensive rats. Biol Pharm Bull 32:1244-1250. https://doi.org/10.1248/bpb.32.1244

McAllen RM, Dampney RA (1990) Vasomotor neurons in the rostral ventrolateral medulla are organized topographically with respect to type of vascular bed but not body region. Neurosci Lett 110:91-96. https://doi.org/10.1016/0304-3940(90)90793-9

Mishima S, Yoshida C, Akino S, Sakamoto T (2005) Antihypertensive effects of Brazilian propolis: identification of caffeoylquinic acids as constituents involved in the hypotension in spontaneously hypertensive rats. Biol Pharm Bull 28:1909-1914. https://doi. org/10.1248/bpb.28.1909

Moreira JD et al (2019) Inhibition of microglial activation in rats attenuates paraventricular nucleus inflammation in Galphai2 protein-dependent, salt-sensitive hypertension. Exp Physiol 104:1892-1910. https://doi.org/10.1113/EP087924

Mozaffari Godarzi S, Valizade Gorji A, Gholizadeh B, Mard SA, Mansouri E (2019) Antioxidant effect of p-coumaric acid on interleukin 1- $\beta$ and tumor necrosis factor- $\alpha$ in rats with renal ischemic reperfusion. Nefrología. https://doi.org/10.1016/j.nefro .2019.10.003 
Mueller SM, Heistad DD (1980) Effect of chronic hypertension on the blood-brain barrier. Hypertension 2:809-812. https://doi. org/10.1161/01.hyp.2.6.809

Muxfeldt ES, Chedier B, Rodrigues CIS (2019) Resistant and refractory hypertension: two sides of the same disease? J Bras Nefrol 41:266-274. https://doi.org/10.1590/2175-8239-JBN-2018-0108

Nataraj C et al (1999) Angiotensin II regulates cellular immune responses through a calcineurin-dependent pathway. J Clin Investig 104:1693-1701. https://doi.org/10.1172/JCI7451

Noda M, Hiyama TY (2015a) The Nax channel: what it is and what it does. Neuroscientist 21:399-412. https://doi.org/10.1177/10738 58414541009

Noda M, Hiyama TY (2015b) Sodium sensing in the brain. Pflugers Arch 467:465-474. https://doi.org/10.1007/s00424-014-1662-4

Nomura $\mathrm{K}$ et al (2018) [Na+] increases in body fluids sensed by central Nax induce sympathetically mediated blood pressure elevations via $\mathrm{H}+-$ dependent activation of ASIC1a. Neuron. https://doi. org/10.1016/j.neuron.2018.11.017

Okamoto Y, Tanaka M, Fukui T, Masuzawa T (2012) Brazilian propolis inhibits the differentiation of Th17 cells by inhibition of interleukin-6-induced phosphorylation of signal transducer and activator of transcription 3. Immunopharmacol Immunotoxicol 34:803-809. https://doi.org/10.3109/08923973.2012.657304

Osborn JW, Collister JP, Guzman P (2008) Effect of peripheral sympathetic nerve dysfunction on salt sensitivity of arterial pressure. Clin Exp Pharmacol Physiol 35:273-279. https://doi.org/10.111 1/j.1440-1681.2007.04827.x

Pácha JÍ (1998) Sodium balance and jejunal ion and water absorption in Dahl salt-sensitive and salt-resistant rats. Clin Exp Pharmacol Physiol 25:220-224. https://doi.org/10.1111/j.1440-1681.1998. t01-9-.x

Park YK, Alencar SM, Aguiar CL (2002) Botanical origin and chemical composition of Brazilian propolis. J Agric Food Chem 50:2502-2506. https://doi.org/10.1021/jf011432b

Park YK, Paredes-Guzman JF, Aguiar CL, Alencar SM, Fujiwara FY (2004) Chemical constituents in Baccharis dracunculifolia as the main botanical origin of southeastern Brazilian propolis. J Agric Food Chem 52:1100-1103. https://doi.org/10.1021/jf021060m

Paulino N et al (2008) Anti-inflammatory effects of a bioavailable compound, artepillin C, in Brazilian propolis. Eur J Pharmacol 587:296-301. https://doi.org/10.1016/j.ejphar.2008.02.067

Peet MM, Isberg EM (1946) The surgical treatment of arterial hypertension. Med Press Egypt 38:176-185

Ramseyer VD, Garvin JL (2013) Tumor necrosis factor- $\alpha$ : regulation of renal function and blood pressure. Am J Physiol Renal Physiol 304:F1231-F1242. https://doi.org/10.1152/ajprenal.00557.2012

Rodrigues SL, Souza Junior PR, Pimentel EB, Baldo MP, Malta DC, Mill JG, Szwarcwald CL (2015) Relationship between salt consumption measured by 24-h urine collection and blood pressure in the adult population of Vitoria (Brazil). Braz J Med Biol Res 48:728-735. https://doi.org/10.1590/1414-431X20154455

Rucker AJ, Rudemiller NP, Crowley SD (2018) Salt, hypertension, and immunity. Annu Rev Physiol 80:283-307. https://doi. org/10.1146/annurev-physiol-021317-121134

Ruiz-Ortega M, Ruperez M, Lorenzo O, Esteban V, Blanco J, Mezzano S, Egido J (2002) Angiotensin II regulates the synthesis of proinflammatory cytokines and chemokines in the kidney. Kidney Int Suppl 62:S12-22. https://doi.org/10.1046/j.1523-1755.62.s82.4.x

Santisteban MM et al (2015) Involvement of bone marrow cells and neuroinflammation in hypertension. Circ Res 117:178-191. https ://doi.org/10.1161/circresaha.117.305853

Santisteban MM, Kim S, Pepine CJ, Raizada MK (2016) Brain-gutbone marrow axis: implications for hypertension and related therapeutics. Circ Res 118:1327-1336. https://doi.org/10.1161/ CIRCRESAHA.116.307709
Santos R et al (2018) The ACE2/angiotensin-(1-7)/MAS axis of the renin-angiotensin system: focus on angiotensin-(1-7). Physiol Rev 98:505-553. https://doi.org/10.1152/physrev.00023.2016

Scheller S, Krol W, Swiacik J, Owczarek S, Gabrys J, Shani J (1989) Antitumoral property of ethanolic extract of propolis in micebearing Ehrlich carcinoma, as compared to bleomycin. Z Naturforsch C J Biosci 44:1063-1065. https://doi.org/10.1515/ znc-1989-11-1231

Schlaich MP et al (2004) Sympathetic augmentation in hypertension: role of nerve firing, norepinephrine reuptake, and angiotensin neuromodulation. Hypertension 43:169-175. https://doi. org/10.1161/01.HYP.0000103160.35395.9E

Sesso HD, Wang L, Buring JE, Ridker PM, Gaziano JM (2007) Comparison of interleukin-6 and C-reactive protein for the risk of developing hypertension in women. Hypertension 49:304-310. https://doi.org/10.1161/01.hyp.0000252664.24294.ff

Shahi F, Ghalamkari M, Mirzania M, Khatuni M (2016) A patient with multiple myeloma and renal cell carcinoma. Int J Hematol Oncol Stem Cell Res 10:56-60

Shen XZ, Li Y, Li L, Shah KH, Bernstein KE, Lyden P, Shi P (2015) Microglia participate in neurogenic regulation of hypertension. Hypertension 66:309-316. https://doi.org/10.1161/hypertensi onaha. 115.05333

Shi P et al (2010) Brain microglial cytokines in neurogenic hypertension. Hypertension 56:297-303. https://doi.org/10.1161/hyper tensionaha.110.150409

Shimizu Y, Suzuki T (2019) Brazilian propolis extract reduces intestinal barrier defects and inflammation in a colitic mouse model. Nutr Res 69:30-41. https://doi.org/10.1016/j.nutres.2019.07.003

Silveira MAD, Teles F, Berretta AA, Sanches TR, Rodrigues CE, Seguro AC, Andrade L (2019) Effects of Brazilian green propolis on proteinuria and renal function in patients with chronic kidney disease: a randomized, double-blind, placebo-controlled trial. BMC Nephrol 20:140. https://doi.org/10.1186/s12882-019-1337-7

Silveira-Nunes $\mathrm{G}$ et al (2020) Hypertension is associated with intestinal microbiota dysbiosis and inflammation in a Brazilian population. Front Pharmacol. https://doi.org/10.3389/fphar.2020.00258

Smithwick RH, Thompson JE (1953) Splanchnicectomy for essential hypertension; results in 1,266 cases. J Am Med Assoc 152:15011504. https://doi.org/10.1001/jama.1953.03690160001001

Spigoni V et al (2017) Bioavailability of bergamot (Citrus bergamia) flavanones and biological activity of their circulating metabolites in human pro-angiogenic cells. Nutrients 9:1328. https:// doi.org/10.3390/nu9121328

Sriramula S, Cardinale JP, Francis J (2013) Inhibition of TNF in the brain reverses alterations in RAS components and attenuates angiotensin II-induced hypertension. PLoS ONE 8:e63847. https ://doi.org/10.1371/journal.pone.0063847

Stanhewicz AE, Larry Kenney W (2015) Determinants of water and sodium intake and output. Nutr Rev 73:73-82. https://doi. org/10.1093/nutrit/nuv033

Stocker SD, Lang SM, Simmonds SS, Wenner MM, Farquhar WB (2015) Cerebrospinal fluid hypernatremia elevates sympathetic nerve activity and blood pressure via the rostral ventrolateral medulla. Hypertension (Dallas, Tex: 1979) 66:1184-1190. https ://doi.org/10.1161/HYPERTENSIONAHA.115.05936

Strabelli TMV, Uip DE (2020) COVID-19 e o Coração \%. J Arquivos Brasileiros de Cardiologia. https://doi.org/10.36660/abc.20200 209

Svendsen UG (1976) Evidence for an initial, thymus independent and a chronic, thymus dependent phase of DOCA and salt hypertension in mice. Acta Pathol Microbiol Scand A 84:523-528. https://doi. org/10.1111/j.1699-0463.1976.tb00150.x

Szliszka E, Kucharska AZ, Sokol-Letowska A, Mertas A, Czuba ZP, Krol W (2013) Chemical composition and anti-inflammatory effect of ethanolic extract of Brazilian green propolis on activated 
J774A.1 macrophages. Evid Based Complement Alternat Med 2013:976415. https://doi.org/10.1155/2013/976415

Tanaka M, Okamoto Y, Fukui T, Masuzawa T (2012) Suppression of interleukin 17 production by Brazilian propolis in mice with collagen-induced arthritis. Inflammopharmacology 20:19-26. https://doi.org/10.1007/s10787-011-0088-2

Teixeira EW, Message D, Negri G, Salatino A, Stringheta PC (2010) Seasonal variation, chemical composition and antioxidant activity of Brazilian propolis samples. Evid Based Complement Alternat Med 7:307-315. https://doi.org/10.1093/ecam/nem177

Teles $\mathrm{F}$ et al (2015) Brazilian red propolis attenuates hypertension and renal damage in 5/6 renal ablation model. PLoS ONE 10:e0116535. https://doi.org/10.1371/journal.pone.0116535

Thomson SC, Deng A, Wead L, Richter K, Blantz RC, Vallon V (2006) An unexpected role for angiotensin II in the link between dietary salt and proximal reabsorption. J Clin Investig 116:1110-1116. https://doi.org/10.1172/JCI26092

Toney GM, Stocker SD (2010) Hyperosmotic activation of CNS sympathetic drive: implications for cardiovascular disease. J Physiol 588:3375-3384. https://doi.org/10.1113/jphysiol.2010.191940

Trott DW et al (2014) Oligoclonal CD8+ T cells play a critical role in the development of hypertension. Hypertension 64:1108-1115. https://doi.org/10.1161/HYPERTENSIONAHA.114.04147

Ueno M, Sakamoto H, Liao Y-J, Onodera M, Huang C-L, Miyanaka H, Nakagawa T (2004) Blood-brain barrier disruption in the hypothalamus of young adult spontaneously hypertensive rats. Histochem Cell Biol. https://doi.org/10.1007/s00418-004-0684-y

Vasdev S, Stuckless J, Richardson V (2011) Role of the immune system in hypertension: modulation by dietary antioxidants. Int $\mathrm{J}$ Angiol 20:189-212. https://doi.org/10.1055/s-0031-1288941

Vogel DY, Heijnen PD, Breur M, de Vries HE, Tool AT, Amor S, Dijkstra CD (2014) Macrophages migrate in an activation-dependent manner to chemokines involved in neuroinflammation. J Neuroinflammation 11:23. https://doi.org/10.1186/1742-2094-11-23

Wade B, Abais-Battad JM, Mattson DL (2016) Role of immune cells in salt-sensitive hypertension and renal injury. Curr Opin Nephrol Hypertens 25:22-27. https://doi.org/10.1097/MNH.0000000000 000183

Wang H, Leenen FHH (2002) Brain sodium channels mediate increases in brain "Ouabain" and blood pressure in Dahl S rats. Hypertension 40:96-100. https://doi.org/10.1161/01.hyp.0000022659 17774.e4

Wang J, Chen J, Chen C, Huang S, Rao X, Zhong J (2012) Elevated Th17 and IL-23 in hypertensive patients with acutly increased blood pressure. Am J Immunol 8:27-32. https://doi.org/10.3844/ ajavsp.2012.27.32

Wei S-G, Yu Y, Zhang Z-H, Felder RB (2015) Proinflammatory cytokines upregulate sympathoexcitatory mechanisms in the subfornical organ of the rat. Hypertension 65:1126-1133. https ://doi.org/10.1161/hypertensionaha.114.05112

Weinberger MH (2006) Pathogenesis of salt sensitivity of blood pressure. Curr Hypertens Rep 8:166-170. https://doi.org/10.1007/ s11906-006-0014-y

Wenzel U, Turner JE, Krebs C, Kurts C, Harrison DG, Ehmke H (2016) Immune mechanisms in arterial hypertension. J Am Soc Nephrol 27:677-686. https://doi.org/10.1681/asn.2015050562

White FN, Grollman A (1964) Autoimmune factors associated with infarction of the kidney. Nephron 1:93-102. https://doi. org/10.1159/000179322

WHO (2012) Guideline: Sodium intake for adults and children. World Health Organization (WHO), Geneva

Wilck N et al (2017) Salt-responsive gut commensal modulates TH17 axis and disease. Nature 551:585-589. https://doi.org/10.1038/ nature 24628
Winklewski PJ, Radkowski M, Wszedybyl-Winklewska M, Demkow U (2015) Brain inflammation and hypertension: the chicken or the egg? J Neuroinflammation 12:85. https://doi.org/10.1186/s1297 4-015-0306-8

Wu C et al (2013) Induction of pathogenic TH17 cells by inducible salt-sensing kinase SGK1. Nature 496:513-517. https://doi. org/10.1038/nature11984

Xiao L et al (2015) Renal denervation prevents immune cell activation and renal inflammation in angiotensin II-induced hypertension. Circ Res 117:547-557. https://doi.org/10.1161/circresaha .115 .306010

Xue B, Thunhorst RL, Yu Y, Guo F, Beltz TG, Felder RB, Johnson AK (2016) Central renin-angiotensin system activation and inflammation induced by high-fat diet sensitize angiotensin II-elicited hypertension. Hypertension 67:163-170. https://doi.org/10.1161/ HYPERTENSIONAHA.115.06263

Yamamoto-Kimura L, Zamora-Gonzalez J, Huerta-Alvarado S, Fajardo-Gutierrez A, Cardoso-Saldana G, Posadas-Romero C (1996) High blood pressure and cardiovascular risk factors in an adult population of Mexico City. Characteristics of the studied population. Arch Med Res 27:213-222

Youn JC et al (2013) Immunosenescent CD8+ T cells and C-X-C chemokine receptor type 3 chemokines are increased in human hypertension. Hypertension 62:126-133. https://doi.org/10.1161/ HYPERTENSIONAHA.113.00689

Yu Y, Zhang ZH, Wei SG, Serrats J, Weiss RM, Felder RB (2010) Brain perivascular macrophages and the sympathetic response to inflammation in rats after myocardial infarction. Hypertension 55:652-659. https://doi.org/10.1161/HYPERTENSIONAHA .109 .142836

Yu Y, Cao Y, Bell B, Chen X, Weiss RM, Felder RB, Wei S-G (2019) Brain TACE (tumor necrosis factor- $\alpha$-converting enzyme) contributes to sympathetic excitation in heart failure rats. Hypertension 74:63-72. https://doi.org/10.1161/hypertensionaha .119 .12651

Zaldivia MTK et al (2017) Renal denervation reduces monocyte activation and monocyte-platelet aggregate formation. Hypertension 69:323-331. https://doi.org/10.1161/hypertensionaha.116.08373

Zera T, Ufnal M, Szczepanska-Sadowska E (2009) Central TNF- $\alpha$ elevates blood pressure and sensitizes to central pressor action of angiotensin II in the infarcted rats. J Physiol Pharmacol 59(Suppl $8): 117-121$

Zhang $\mathrm{T}$ et al (2015) Excess salt exacerbates blood-brain barrier disruption via a $\mathrm{p} 38 / \mathrm{MAPK} / \mathrm{SGK} 1-d e p e n d e n t$ pathway in permanent cerebral ischemia. Sci Rep 5:16548. https://doi.org/10.1038/ srep16548

Zhang D, Wang C, Cao S, Ye Z, Deng B, Kijlstra A, Yang P (2015) High-salt enhances the inflammatory response by retina pigment epithelium cells following lipopolysaccharide stimulation. Mediators Inflamm 2015:197521. https://doi.org/10.1155/2015/19752 1

Zhang $\mathrm{H}$ et al (2019) Hepatoprotective effect of capsaicin against concanavalin A-induced hepatic injury via inhibiting oxidative stress and inflammation. Am J Transl Res 11:3029-3038

Zheng H-Y et al (2020) Elevated exhaustion levels and reduced functional diversity of $\mathrm{T}$ cells in peripheral blood may predict severe progression in COVID-19 patients. Cell Mol Immunol. https:// doi.org/10.1038/s41423-020-0401-3

Publisher's Note Springer Nature remains neutral with regard to jurisdictional claims in published maps and institutional affiliations. 